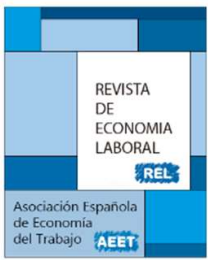

\title{
LAS REFORMAS DEL MERCADO DE TRABAJO EN ESTADOS UNIDOS (1973-2013) Y SUS IMPACTOS SOBRE LA DESIGUALDAD DE INGRESOS
}

\author{
Iván González Sarro ${ }^{1 *}$ \\ * Instituto Universitario de Investigación en Estudios Latinoamericanos (IELAT)- \\ Universidad de Alcalá
}

Recibido Noviembre 2018; Aceptado Enero 2019

\section{Resumen}

El propósito del artículo es mostrar la evolución del mercado de trabajo de los Estados Unidos en el periodo 1973-2013, realizando un análisis detallado de las reformas laborales más relevantes llevadas a cabo y evaluando su impacto sobre la desigualdad de ingresos. La hipótesis de trabajo básica que se tratará de documentar es que los distintos presidentes a lo largo del periodo investigado no han articulado políticas de progreso para los trabajadores estadounidenses. Según nuestra interpretación, a partir de los años ochenta del siglo XX, se produjo en Estados Unidos un cambio en el paradigma económico y este nuevo modelo económico y su proyección al ámbito laboral ha repercutido en la desigualdad de ingresos.

Palabras clave: Estados Unidos, política del mercado de trabajo, reformas laborales, politica neoliberal.

Clasificación JEL: J08, J38, J58, J88, N320

\footnotetext{
${ }^{1}$ Este artículo forma parte de la Tesis Doctoral del autor, titulada "Neoliberalismo y polarización social: México, Estados Unidos, Francia y España (1973-2013), en perspectiva comparada", dirigida por el Dr. Pedro Pérez Herrero, catedrático de Historia de América de la Universidad de Alcalá y Director del Instituto Universitario de Investigación en Estudios Latinoamericanos (IELAT) de la Universidad de Alcalá, y defendida en esta Universidad el 23 de marzo de 2018. Mi agradecimiento al profesor Pérez Herrero por su docencia, su lectura atenta, rigurosa y rápida, sus comentarios y correcciones, siempre pertinentes. Agradezco igualmente al IELAT y al Banco Santander la beca concedida acogida al "I Programa de Becas IELAT-Santander (año 2016) para la realización de tesis doctorales". Dirección para correspondencia: Instituto Universitario de Investigación en Estudios Latinoamericanos (IELAT)-Universidad de Alcalá, Calle Trinidad n ${ }^{\circ}$ 1, Colegio de Trinitarios, 28802, Alcalá de Henares (Madrid, España). Correo electrónico: ivan.gonzalezs@edu.uah.es.
}

(C) Revista de Economía Laboral 


\begin{abstract}
The purpose of the paper is to show the evolution of the labor market of the United States in the period 1973-2013, making a detailed analysis of the most relevant labor reforms carried out and assessing their impact on income inequality. The basic work hypothesis that will be tried to document is that the different presidents throughout the investigated period have not articulated policies of progress for the American workers. According to our interpretation, from the eighties of the twentieth century, there was a change in the economic paradigm in the United States and this new economic model and its projection into the labor sphere has had repercussions on income inequality.
\end{abstract}

Key words: United States, labor market policy, labor reforms, neoliberal policy.

JEL Classification: J08, J38, J58, J88, N320

\title{
1. Introducción
}

El mercado laboral constituye la principal fuente de obtención de rentas en una economía y lo que ocurra en él marcará necesariamente la distribución de la renta en el país. Podría decirse que en muchos países la desigualdad comienza en el mercado de trabajo, pudiendo constituir este una causa subyacente en el aumento de la desigualdad, si no el principal factor generador de desigualdades en muchos países. Las rentas del trabajo, y en particular las rentas salariales, representan la mayor parte de los ingresos de muchas familias, por lo que los niveles de desigualdad que pueden darse a nivel salarial afectan, sin duda, a la distribución general de los ingresos. Estos niveles de desigualdad salarial, en especial la incidencia del empleo mal remunerado, así como el nivel y la tendencia del desempleo en cada país, pueden verse influenciados de forma importante por las características y el funcionamiento del mercado de trabajo. Por ello, las políticas en relación al mercado de trabajo pueden tener unos efectos muy relevantes sobre la desigualdad. La acción política en relación con los mercados laborales se manifiesta en las decisiones presupuestarias y, además, en las actividades de regulación de los mismos, que pueden producir consecuencias de gran trascendencia para los agentes que actúan en los mercados de trabajo (Ruiz-Huerta, 1998: 19).

Dentro de estas políticas, cabe diferenciar entre un conjunto de factores que directamente pueden suponer una fuente de desigualdad ligada con el mercado de trabajo y otros aspectos que están más vinculados con la vertiente institucional, aunque también pueden jugar un papel significativo e impactar sobre la desigualdad. En el primer grupo de factores, cabe referirse al nivel de desempleo, el aumento o disminución de los salarios, la dispersión de los mismos, el grado de centralización del sistema de negociación y determinación salarial, la 
existencia o no de un salario mínimo obligatorio, entre otros. En el segundo grupo de acciones, cabe integrar la regulación en materia de contratación y despido, el sistema de protección social y, en particular, el diseño de las prestaciones por desempleo y la configuración de las políticas activas relacionadas con el mercado de trabajo, los programas de formación continua de los trabajadores, etc.

Como se sabe, el mercado de trabajo se ha visto afectado en las últimas décadas por la deslocalización, la globalización y el cambio tecnológico, variables que han provocado la pérdida de mucho empleo en sectores industriales en otros tiempos potentes así como recortes en los salarios. Por otro lado, las "reformas estructurales" llevadas a cabo según un nuevo paradigma económico han provocado la "liberalización de los mercados laborales", con frecuencia entendida como recortes salariales, debilitamiento de los mecanismos de negociación colectiva y una mayor diferenciación salarial entre sectores y empresas, produciéndose un cambio en las relaciones laborales, caracterizado entre otros rasgos, por una disminución del poder de los sindicados y un incremento del poder del capital.

Hay un consenso fundamental en establecer un punto de inflexión importante a nivel internacional a partir de 1973 como momento en que se empieza a pasar en los países centrales del capitalismo fordista a las políticas neoliberales aplicadas con mayor o menor intensidad en las últimas décadas. De acuerdo con esta reorientación de las políticas económicas, según el nuevo paradigma económico, en muchos países, entre ellos sin duda en los Estados Unidos, de una forma general, se abandonaron las políticas públicas keynesianas más intervencionistas, que se habían aplicado hasta entonces y que se centraban sobre todo en reducir las elevadas tasas de desempleo y, en lo posible, la desigualdad de ingresos.

Por otra parte, según un estudio de la OCDE, Estados Unidos fue el país que registró un mayor incremento de la desigualdad dentro de los países de la OCDE entre mediados de la década de 1980 y mediados de la década de 2000 (OECD, 2011: 228). De acuerdo con diversas estadísticas históricas sobre la desigualdad del ingreso a lo largo del tiempo, proporcionadas por el United States Census Bureau, en los Estados Unidos las desigualdades de renta habrían aumentado de forma apreciable desde la segunda mitad de los años setenta del siglo XX, según los datos de dos indicadores relevantes de medida de la desigualdad —el 
Índice de Gini y la distribución del ingreso por grupos de población ${ }^{2}$ La desigualdad en este país, entre 1973 y 2013, presentó un perfil paulatinamente creciente, causado fundamentalmente por el elevado, rápido y continuo crecimiento del ingreso medio de los hogares ubicados en los grupos más elevados de ingresos superiores, mostrando una mayor dualización de la distribución, hasta el punto de que podría hablarse de una auténtica polarización social, al observarse un debilitamiento de los grupos de renta media y de crecimiento de los grupos extremos, pobres y ricos. Conviene resaltar que la mayor parte del aumento de la desigualdad en la distribución de ingresos tuvo lugar en los años ochenta y noventa.

El patrón temporal del cambio experimentado en los Estados Unidos a lo largo del período investigado resulta bastante claro: las familias situadas en el extremo superior de la distribución de ingresos obtuvieron ganancias de renta muy superiores a las localizadas en los percentiles inferiores ${ }^{3}$. Y, además, dentro de las rentas altas, es el decil más elevado el que más vio aumentar su participación. Como consecuencia de ese crecimiento desigual de la renta, se puede afirmar que la distribución del ingreso era sustancialmente más desigual en 2013 que en 1973. La diferencia entre ricos y pobres en los Estados Unidos ha aumentado en este lapso de tiempo.

Por todo ello, resulta pertinente a nuestro juicio analizar las conexiones entre el mercado de trabajo y la distribución final de la renta así como el papel desempeñado por las políticas públicas que afectan a las rentas primarias del mercado laboral en las tendencias observadas en

${ }^{2}$ El Índice de Gini se habría incrementado en casi un 20\% entre $1977(0,402)$ y 2013 $(0,482)$ y la evolución del porcentaje del ingreso de todas las familias estadounidenses mostraría cómo el porcentaje de la renta total del $80 \%$ inferior de las familias fue disminuyendo, mientras que el porcentaje del $20 \%$ superior aumentó considerablemente durante el mismo período. [Base de datos disponible en: https://www.census.gov/hhes/www/income/data/historical/inequality/, descargados el 26 de diciembre de 2017].

${ }^{3}$ No obstante, debe resaltarse que algunos autores defienden que el aumento de la desigualdad en EE.UU. se ha exagerado si se analizan los datos de consumo real de los hogares, debido a que no se ha tenido en cuenta que ricos y pobres han afrontado distintos niveles de inflación a lo largo del tiempo. Así, Gordon observa que los pobres consumen mucho más intensivamente que los ricos alimentos, ropas y aparatos electrónicos, en gran medida importados de China, que adquieren baratos en almacenes como Wal-Mart, mientras que los ricos gastan mucho dinero en bienes y servicios cuyos precios relativos han aumentado, como viviendas en zonas residenciales de las grandes áreas metropolitanas, educación privada, salud, servicios de jardinería, etc. (Gordon, 2009: 2627). A similares conclusiones llegan Meyer y Sullivan, analizando indicadores sobre renta, consumo y privación material desde los años ochenta (2011: 33). 
la evolución de la desigualdad. Ese es el objetivo básico de este trabajo, analizar las políticas públicas llevadas a cabo en Estados Unidos así como los cambios y reformas introducidas en el mercado laboral a lo largo del período investigado que han podido incidir en la evolución y comportamiento de los distintos componentes del mercado laboral, que, a su vez, han podido influir en la desigualdad de ingresos.

Frente a la doctrina tradicional — según la cual el aumento de las desigualdades ha sido el resultado "normal" de la globalización y del uso de más capital y tecnologías avanzadas en el proceso de producción-, se sostiene por nuestra parte que en los últimos cuarenta años, las modificaciones llevadas a cabo en el ámbito laboral con arreglo al nuevo paradigma de "flexibilidad del mercado laboral" han desempeñado un papel clave en el aumento de la desigualdad, exacerbando la desigualdad de los ingresos, y haciendo que la carga de la adaptación a la globalización y al progreso tecnológico recaiga en los asalariados y en los grupos de rentas medias y bajas. Sostenemos que los impactos de la globalización y el cambio tecnológico dependen de la forma en que las fuerzas de estos fenómenos interactúen con las políticas económicas, y más concretamente con las relacionadas con el mercado de trabajo. Las transformaciones estructurales, como suponen fenómenos como la globalización o la tecnología, no tienen porqué necesariamente crear mayor desigualdad si se adoptan las políticas laborales, salariales y de condiciones de trabajo en general adecuadas. El problema ha sido que las políticas no han sido las idóneas.

Nuestro planteamiento está en sintonía con el de distintos autores, como Stiglitz, para quien "la desigualdad no es inevitable, ni el resultado inexorable de las leyes de la economía, sino consecuencia de nuestras políticas y estrategias" (Stiglitz, 2017: 16). También es coherente con el de Atkinson, quien señala que, en contra de la creencia generalizada, algunos de los factores que a menudo se identifican como responsables del aumento de la desigualdad, como la globalización, el cambio tecnológico, la flexibilización de los mercados de trabajo o el repliegue de las políticas de impuestos y gastos, ni quedan lejos del control de los poderes públicos ni son exógenos al sistema económico y social. Así, argumenta este autor, la globalización es el resultado de decisiones tomadas por organismos internacionales, por gobiernos nacionales, por corporaciones y por individuos como trabajadores $\mathrm{y}$ consumidores. La dirección del cambio tecnológico es el producto de las decisiones de las empresas, los investigadores y los gobiernos (Atkinson, 2015: 82-83). En sentido similar, el profesor Fontana defiende la idea de que "el triunfo de la desigualdad [...] no ha surgido de un proceso 
«natural», fruto de la actuación de las fuerzas del mercado, sino que es el resultado de medidas de naturaleza política" (Fontana, 2017: 598). Sostiene el autor que "entre los mecanismos que producen esta acumulación en lo más alto de la tabla [el 1\%o de los más ricos], dos de los más importantes, la disminución del gasto salarial y de los impuestos sobre las ganancias, dependen de decisiones políticas, como son las que regulan las «reformas laborales» y la legislación fiscal" (Fontana, 2017: 606). Chomsky va más allá al afirmar que las altas cotas de desigualdad que se han alcanzado en los EE.UU., similares a las de finales de la década de 1920, "no es el resultado de los misteriosos mecanismos del mercado o de leyes económicas, sino, otra vez, en gran medida del apoyo «indispensable» y la iniciativa de un Gobierno que está, en gran medida, en manos de las empresas" (Chomsky, 2016: 184).

En definitiva, sostenemos, junto con Laval y Dardot, que el neoliberalismo, definido como "cierta norma de vida en las sociedades occidentales", desde hace más de treinta años, "preside las políticas públicas" y tiende a "estructurar y organizar las acción de los gobernantes" (Laval y Dardot, 2015: 14-15). Argumentamos, por otro lado, que estas políticas públicas nacionales se han orientado desde el lado de la oferta - no de la demanda agregada-, y han impactado sobre los niveles de desigualdad al provocar un aumento del desempleo, que los salarios hayan ido a la zaga de la productividad y, en general, un empeoramiento de las condiciones de los mercados de trabajo.

Conviene precisar en este apartado introductorio que este artículo se centra en el mercado de trabajo. Se es consciente de que los gobiernos pueden influir decisivamente en las rentas de las personas y las familias, y consecuentemente sobre la desigualdad de ingresos, mediante una triple vía. En primer lugar, disminuyendo una parte de las mismas a través de los impuestos. En segundo lugar, incrementándolas por medio de prestaciones sociales. En tercer lugar, actuando directamente sobre las rentas primarias recibidas en el mercado de trabajo, en función de una serie de factores asociados al nivel de centralización o desregulación del mismo así como otros de índole institucional (costes de despidos, salarios mínimos, densidad y poder de los sindicatos, entre otros). No se abordan en este trabajo el análisis de la política fiscal ni la relacionada con el gasto público social como factores redistributivos o compensadores o no de la desigualdad de ingresos.

El trabajo se organiza de la siguiente manera. En el apartado segundo se desarrolla un breve comentario sobre los antecedentes del mercado de trabajo estadounidense a fin de comprender los aspectos relevantes del mercado laboral actual. En el apartado tercero se 
examinan las reformas laborales llevadas a cabo durante el período bajo análisis, analizándose su impacto sobre la desigualdad económica. Las conclusiones más relevantes del trabajo se recogen en el apartado cuarto.

\section{El mercado de trabajo de los Estados Unidos: antecedentes}

Desde una perspectiva amplia, para poder comprender el modelo del mercado de trabajo en Estados Unidos y algunos de sus rasgos definitorios actuales - flexibilidad e inestabilidad laboral, desregulación, movilidad de la mano de obra, adaptación a las circunstancias cambiantes de la oferta y la demanda, subcontratación, entre otroshabría que remontarse al proceso de migración transatlántica en el período colonial durante los siglos XVII y XVIII, que conllevó el asentamiento europeo y el desplazamiento concomitante de la población nativa, así como al proceso de migración internacional en los siglos XIX y XX, después de la Guerra de Independencia (1775-1783), que marcaría un punto de inflexión en el desarrollo de las instituciones del mercado laboral.

En efecto, desde el comienzo de la colonización europea se produjo un movimiento de población como consecuencia de la escasez de mano de obra en relación con la abundante tierra y los recursos naturales. La escasez de mano de obra elevó la productividad laboral y permitió a los estadounidenses típicos disfrutar de un nivel de más alto que sus pares europeos. Sin embargo, el alto coste del viaje a través del Atlántico y los riesgos significativos que planteaba la colonización en las regiones fronterizas contrarrestaron el incentivo a la migración. Con el tiempo, los avances técnicos reducirían los costes de comunicación y transporte. Durante los siglos XVII y XVIII, una variedad de instituciones del mercado laboral se desarrollaron para facilitar el movimiento del trabajo en respuesta a las oportunidades creadas en el territorio estadounidense. Mientras que algunos inmigrantes emigraron por su cuenta, la mayoría eran esclavos indocumentados o esclavos africanos (Rosenbloom, 2008).

Como explica Grubb, debido al coste del pasaje - que superaba los ingresos de medio año para un inmigrante británico típico y el ingreso de un año completo para un inmigrante alemán típico- solo una pequeña porción de los inmigrantes europeos podía pagar su viaje a América (Grubb, 1985: 855-868). Muchos lo hicieron mediante la firma de contratos, comprometiéndose a trabajar durante un número fijo de años en el futuro - su trabajo era su único activo viable - con los comerciantes 
británicos, que luego, después de la llegada de los barcos a América, vendían estos contratos a los colonos. En otros casos, los migrantes tomaban prestado dinero para su pasaje, comprometiéndose a pagar a los comerciantes vendiéndose como sirvientes en EE.UU., una práctica conocida como "servidumbre del redentor" (Grubb, 1986: 407-418).

La otra fuente principal de trabajo para las colonias fue la migración forzada de esclavos africanos. La esclavitud se había introducido en las Indias Occidentales en una fecha temprana, pero no fue hasta finales del siglo XVII cuando comenzó a importarse un número significativo de esclavos en las colonias continentales. Galenson explica la transición de la mano de obra contratada de Europa a la mano de obra africana esclavizada como resultado de los cambios en las condiciones de oferta y demanda en Inglaterra y en el mercado de esclavos transatlántico. Las condiciones en Europa mejoraron después de 1650, reduciendo el suministro de empleados con contrato, mientras que al mismo tiempo una mayor competencia en el comercio de esclavos estaba reduciendo el precio de los esclavos (Galenson, 1984: 1-26). Como señala Morgan (1971: 595-611), en cierto sentido, la experiencia inicial de las colonias con los sirvientes contratados allanó el camino para la transición a la esclavitud. Al igual que los esclavos, los sirvientes contratados no tenían libertad, y la propiedad de su trabajo podía transferirse libremente de un propietario a otro. A diferencia de los esclavos, sin embargo, podrían esperar finalmente ser libres.

Con el tiempo surgió una marcada división regional en las instituciones del mercado laboral en América colonial. El uso de esclavos se concentró en Chesapeake y en el Bajo Sur, donde la presencia de cultivos de exportación básicos (arroz, índigo y tabaco) proporcionó recompensas económicas para expandir la escala de cultivo más allá del tamaño que se podía lograr con la mano de obra familiar. Los inmigrantes europeos (principalmente sirvientes contratados) tendieron a concentrarse en las colonias Chesapeake y Middle, donde los sirvientes podían esperar encontrar las mejores oportunidades para dedicarse a la agricultura una vez que hubieran completado su período de servicio (Rosenbloom, 2008).

La independencia de los Estados Unidos marcó un punto de inflexión en el desarrollo de las instituciones del mercado laboral. En 1808 el Congreso prohibió la importación de esclavos. Mientras tanto, el uso de la servidumbre por contrato para financiar la migración de inmigrantes europeos cayó en desuso. Como resultado, la mayoría de las migraciones subsiguientes fueron, al menos nominalmente, migración libre (Rosembloom, 2008). 
$\mathrm{Al}$ mismo tiempo que el desarrollo económico estadounidense creó desequilibrios internacionales entre la oferta y la demanda laboral, también creó un desequilibrio interno. La tierra fértil y los abundantes recursos naturales atrajeron a la población hacia las regiones menos densamente pobladas del oeste. En el transcurso del siglo XIX, los avances en el transporte y las innovaciones tecnológicas alentaron el crecimiento de la manufactura y aumentaron la urbanización. El movimiento de la población y la actividad económica desde el litoral oriental hacia el interior del continente y desde las zonas rurales a las urbanas en respuesta a estos incentivos es un rasgo relevante de la historia económica de los Estados Unidos en aquel siglo. Las diferencias en los procesos de migración hacia el oeste en el Norte y el Sur —con profundos efectos en los patrones de asentamiento y desarrollo regional, en el Sur, basados en los esclavos, mientras que en el Norte, la migración se produjo a través de la reubicación de pequeñas granjas familiares-se reflejaron en la divergencia de las tasas de urbanización, inversión en infraestructura de transporte, empleo en manufactura y densidad de población, todas más altas en el Norte que en el Sur en 1860 (Wright, 1986: 19-29).

La inmigración se convirtió en un tema político cada vez más controvertido a finales del siglo XIX y principios del XX. Mientras que los empleadores y algunos grupos de inmigrantes apoyaron la continua inmigración, hubo un creciente sentimiento nativista entre otros segmentos de la población. Los sentimientos anti-inmigrantes surgieron de una mezcla de efectos económicos percibidos y preocupación por las implicaciones de las diferencias étnicas, religiosas y culturales entre los inmigrantes y los nativos. En 1882, el Congreso aprobó la Ley de Exclusión de China. Los posteriores esfuerzos legislativos para imponer nuevas restricciones a la inmigración se aprobaron por el Congreso, pero se hundieron en los vetos presidenciales. Sin embargo, el equilibrio de las fuerzas políticas cambió a raíz de la Primera Guerra Mundial. En 1917 se impuso por primera vez un requisito de alfabetización, y en 1921 se aprobó una Ley de contingentes de emergencia (Goldin, 1993).

Por otro lado, el crecimiento de las grandes fábricas contribuyó al aumento de las tensiones laborales a fines del siglo XIX y principios del XX. Problemas como las horas de trabajo, la seguridad y las condiciones de trabajo surgieron entre los empleadores y los trabajadores. Una solución era establecer mecanismos para la negociación colectiva, por lo que los años posteriores a la Guerra Civil estadounidense se caracterizaron por un progreso significativo en el crecimiento de la mano de obra organizada (Friedman, 2008). Sin embargo, los esfuerzos de 
sindicación se encontraron con la fuerte oposición de los empleadores, y sufrió los obstáculos creados por el sesgo del sistema legal estadounidense para proteger la propiedad y la libertad de contrato. Bajo la interpretación legal predominante, los tribunales consideraban a menudo que las huelgas eran conspiraciones para restringir el comercio. Hasta el New Deal, en que la legislación laboral adquirió una importancia política, los sindicatos no obtuvieron una amplia aceptación y un derecho legal a negociar. Sin embargo, incluso hoy en día, los esfuerzos de organización sindical a menudo se encuentran con una considerable hostilidad (Rosenbloom, 2008).

La crisis económica de la década de 1930, tras la que los Estados Unidos dejaron de ser el ejemplo de «tierra prometida», desencadenó una ola de intervenciones gubernamentales en el mercado laboral. Durante la década de 1930, el gobierno federal otorgó a los sindicatos el derecho de organizarse legalmente, estableció un sistema de seguro de desempleo, de invalidez y de vejez, y estableció disposiciones relativas a salarios mínimos y pago de horas extras.

Así, en 1933, dentro de las políticas del New Deal, la Ley Nacional de Recuperación Industrial (National Industrial Recovery Act, también conocida como NIRA), incluía disposiciones que legalizaban el derecho de los sindicatos a negociar colectivamente. Aunque la NIRA finalmente fue declarada inconstitucional, las disposiciones laborales clave de la Ley fueron reinstaladas en la Ley Nacional de Relaciones Laborales (National Labor Relations Act-NLRA), o también llamada "Ley Wagner" de 1935. Efectivamente, la cláusula 7.a de la NIRA, que establecía que los trabajadores podían elegir a sus representantes en estos términos: «los empleados tienen el derecho a organizarse y negociar colectivamente a través de representantes elegidos por ellos mismos, y estarán libres de la interferencia, de los obstáculos y coerción de los patronos", fue rescatada por la "Ley Wagner". Desde el principio, esta cláusula no aseguró «el derecho de los trabajadores a organizarse en sindicatos independientes», según Wolters (1990: 23). La Ley, interpretada a grandes rasgos, contentaba a los líderes sindicales pero existía «poca resistencia institucional para evitar las evasiones sistemáticas de la ley» opinaba Vittoz (1987: 138). Pese a que la Ley impulsaba la organización laboral, supuso cierta decepción pues no se respetaba, debido, en parte, a su ambigüedad y al poco deseo de los patronos de reconocer la ley. De este modo, muchos hombres de negocios se dieron cuenta de que la legislación no especificaba la manera en la que los representantes debían ser elegidos y buscaron cumplir con los términos de la Ley, estableciendo sindicatos controlados por la directiva de las empresas - los Company 
Unions-. Es decir, a pesar de la que NIRA expresaba las condiciones de la negociación colectiva, no puso los métodos para garantizarla. Era un símbolo sin resultados prácticos, que expresaba algunos principios sobre la conveniencia de que los trabajadores se organizasen, pero que no obligaba a los patronos a negociar y no preveía medio alguno para hacerlo. Además las disposiciones resultaban ambiguas $\mathrm{y}$, en consecuencia, fáciles de evadir. A pesar de suponer un fracaso por no ser respetada por la patronal, esta cláusula tuvo una importante influencia posterior, al integrarse en la NLRA de 1935 (Arroyo, 2002).

Esta Ley declaró que era una política de Estados Unidos "promover la práctica y el procedimiento de la negociación colectiva y [...] proteger el ejercicio de los trabajadores de su total libertad para asociarse, auto-organizarse y para designar a los representantes de su propia elección, con el propósito de negociar los términos y condiciones de sus empleos u otra ayuda mutua o protección"4. Por ello, la afiliación sindical aumentó muy rápidamente después de 1935 -desde aproximadamente el $12 \%$ de la fuerza laboral no agrícola a casi el $30 \%$ y hacia finales de la década de 1940 había alcanzado un máximo del 35\%, en el que se estabilizó. Sin embargo, desde la década de 1960, la afiliación sindical comenzó a disminuir constantemente.

También en 1935, la Ley de Seguridad Social (Social Security Act) estableció un plan federal de seguro de desempleo, que se hizo operativo en asociación con los gobiernos estatales y fue financiado mediante un impuesto a los empleadores. También creó un seguro gubernamental de vejez e invalidez. Esta Ley, que causó una gran controversia en los Estados Unidos al entrar en vigor, pues círculos conservadores la acusaron de fomentar una injusticia en el gasto público, en tanto que personas que había trabajado durante pocos años podrían acogerse al pago de pensiones, constituyendo una carga gravosa para el gobierno federal y para los trabajadores activos que seguían aportando, fue modificada en sucesivas ocasiones, siendo una de las más importantes la que se llevó a cabo en 1965, cuando los seguros de Medicaid y Medicare se integraron al sistema. En 1938, la Ley Federal de Normas Estándar del Trabajo (Fair Labor Standards Act-FLSA) estableció salarios mínimos y el pago de las horas extras. Al principio, la cobertura de estas disposiciones fue limitada, pero se fue incrementando constantemente en años posteriores hasta cubrir la mayoría de las industrias.

${ }_{4}^{4} 29$ U.S.C. $§ 151$. [Disponible en: https://www.nlrb.gov/resources/national-labor-relationsact, consultado el 6 de enero de 2018]. 
En la época de la posguerra, el gobierno federal expandió su papel en la gestión de los mercados laborales tanto directamente como a través del establecimiento de regulaciones de seguridad ocupacional y leyes contra la discriminación, por ejemplo, e indirectamente, a través de sus esfuerzos por alcanzar el pleno empleo mediante su política económica. La Ley de Empleo de 1946 (Employment Act of 1946) estableció como objetivo nacional el "cumplimiento del derecho a oportunidades plenas de empleo remunerado útil a tasas justas de compensación de todas las personas capaces, dispuestas y que buscan trabajar" ${ }^{5}$. En aquellos momentos, los liberales querían poner énfasis en el "pleno empleo", pero los conservadores tenían el control y no lo entendieron. Sostiene Stein que el hecho de no aprobar una "ley de pleno empleo" fue tan importante como la decisión de aprobar la "Ley de empleo" (Stein, 1969: 197). A partir de esta Ley se construyó la estructura del mercado de trabajo después de la II Guerra Mundial, según Osterman (1999: 10). En el año 1947, la Ley de Relaciones Laborales (Labor Management Relations Act, 1947), más conocida como Ley Taft-Hartley, modificó algunas de las disposiciones de la Ley Wagner y marcó el comienzo de la edad de oro del trabajo organizado en los Estados Unidos.

Después de estas leyes, una nueva expansión de la participación federal en los mercados laborales iba a comenzar en 1964, en el apogeo de la "Gran Sociedad" ("Great Society"), con la aprobación de la Ley de Derechos Civiles (The Civil Rights Act of 1964), que prohibió la discriminación en el empleo tanto contra las minorías como contra las mujeres. En 1967, se promulgó la Ley de Discriminación y Empleo por Edad (The Age Discrimination in Employment Act of 1967), que prohibió la discriminación contra las personas de cuarenta a setenta años en lo que afectaba a la contratación, el despido, las condiciones de trabajo y el salario (Goldin, 2000: 614).

Apuntan Levy y Temin (2007) que todo este entramado institucional de la posguerra fue reflejo del esfuerzo del gobierno federal para distribuir ampliamente las ganancias del crecimiento. El mismo, junto al marco de negociación establecido en el Tratado de Detroit ${ }^{6}$,

515 U.S.C. §151. [Disponible en: https://www.law.cornell.edu/uscode/text/15/1021, consultado el 6 de enero de 2018].

${ }^{6} \mathrm{El}$ Tratado de Detroit fue el acuerdo laboral más importante de la posguerra, firmado entre la United Auto Workers (UAW) y los tres grandes de Detroit (Ford, GM y Chrysler) en 1950. Por este contrato colectivo, la UAW se comprometió a restringir su derecho a ir a la huelga a cambio de ajustes salariales indexados a la inflación, importantes ventajas en materia de salud, retiro, despidos y vacaciones. Este arreglo fue el modelo seguido en otras industrias durante veinte años hasta la década de los años setenta (Nadal, 2010). 
impuestos progresivos y un salario mínimo elevado, propiciaron un aumento considerable del ingreso medio del 99\% de las familias estadounidenses entre 1955-1975 (Nadal, 2010). Señalan los primeros autores que se produjo un crecimiento amplio de los ingresos que benefició la vida económica diaria de los estadounidenses en tres dimensiones principales. En primer lugar, ello se tradujo en una expansión de la clase media. Así, en 1964, el 44\% de la población se incluía como clase media, frente al $37 \%$ en 1952 . Matizan que esta expansión de la clase media no se reflejaba significativamente en unos ingresos más igualitarios, sino en un rápido crecimiento de los ingresos por el que más familias podían permitirse una vivienda unifamiliar, uno o más automóviles, y los otros elementos característicos de un estilo de vida de clase media. Como consecuencia de estos ingresos crecientes, se produjo, en segundo lugar, una movilidad ascendente masiva, reflejado en el hecho de que gran parte de una generación podía vivir mejor de lo que sus padres vivieron, aunque sus posiciones relativas en la distribución del ingreso fueran similares. En tercer lugar, se creó una red de seguridad para el cambio de trabajo, ya que al aumentar tan rápidamente, cualquier persona que perdía su trabajo podía encontrar otro en un tiempo razonablemente corto y volver a recuperar su nivel salarial (Levy y Temin, 2007: 30-31).

Durante este período — la "Edad de Oro" desde 1947 a 1973- la productividad laboral y el ingreso familiar medio se duplicaron, aproximadamente. La remuneración media de los trabajadores a tiempo completo y la productividad laboral creció a la misma tasa desde 1950 hasta finales de los años de 1970. Simultáneamente, la igualdad de ingresos aumentó a medida que los ingresos de los grupos superiores percentil del $0,5 \%$ - crecieron más lentamente que la productividad laboral, según los datos aportados por Levy y Temin (2007: 4).

Esta estructura institucional del mercado de trabajo estadounidense iba a ser "destruida" a partir de finales de la década de 1970, según Osterman (1999: 6). La reversión de todo ello iba a cristalizar en un patrón institucional conocido como el Consenso de Washington, según Levy y Temin (2007: 1). Según Nadal (2010), a partir del estancamiento en la tasa de ganancia en las industrias medulares de la economía estadounidense a partir del final de los años sesenta, provocó el "desencadenamiento de la ofensiva del capital en contra de la clase trabajadora en la década de los setenta, en un esfuerzo por cambiar el patrón de distribución del ingreso", procediéndose al "desmantelamiento gradual de las instituciones que mantuvieron el pacto social de la posguerra y su esquema de crecimiento sostenido de salarios". Con la 
quiebra de este marco institucional, basado, como se ha dicho, en el pacto social (sindicatos-grandes empresas), en el compromiso del Estado con el crecimiento y el pleno empleo y en el consenso internacional que garantizaba la hegemonía monetaria del dólar, desapareció el modelo de crecimiento que había funcionado en Estados Unidos en las décadas anteriores y con ello "los sucesivos círculos virtuosos entre la expansión de la demanda agregada, la distribución de la renta y el crecimiento de la productividad", en palabras de Palazuelos (2010: 93). La erosión y remoción de este entramado de "viejas leyes" ayudan a entender el porqué de algunos impactos negativos que se han producido desde entonces, como la disminución de la seguridad en el empleo, el deterioro de las condiciones laborales como los salarios, la movilidad en el trabajo, el aumento de la dispersión salarial, las nuevas formas de contratación, etc. (Osterman, 1999: 7-11).

\section{Las reformas del mercado laboral estadounidense en el periodo 1973-2013 y su impacto sobre la desigualdad de ingresos}

\subsection{Presidencia de James E. Carter (1977-1981)}

Como se ha dicho, este proceso de "destrucción" del entramado laboral institucional se iba a hacer ya patente a finales de la década de los años setenta. Durante estos años, la demanda de revisiones en la legislación laboral se había hecho cada vez más importante para los activistas sindicales. Los sindicatos estaban ansiosos por avanzar en algún tipo de reforma de la legislación laboral tan pronto como las condiciones políticas lo permitieran, tal como explica Dark III (2008: 11$12)$.

La elección de James E. Carter Jr. (1977-1981), junto con la persistencia de importantes mayorías demócratas tanto en la Cámara como en el Senado, presentó la oportunidad de buscar el cambio una vez más. La American Federation of Labor-Congress of Industrial Organizations (AFL-CIO) aprobó la legislación que implementaba un conjunto interrelacionado de reformas en las leyes laborales de la nación, diseñadas para mejorar al menos algunas de las causas del declive sindical, entre ellas, por ejemplo, denegar contratos federales a las empresas declaradas culpables de violar la legislación laboral. En julio de 1977 se presentó en la Cámara la propuesta de la ley laboral — Labor Law Reform Act- La reforma venía motivada "to make the laws which 
govern labor-management relations work more efficiently, quickly and equitably"7. Los sindicatos estaban convencidos de que iba a ser aprobada. El proyecto fue aprobado por la Cámara de Representantes por 257 votos favorables frente a 163 en contra, pero, objeto de una dura campaña hostil de las organizaciones empresariales, se eternizó en el Senado, hasta que, finalmente, fue retirado el 15 de junio de 1978 (Dark III, 2008: 13 y Dark III, 2009: 23-26). Casi simultáneamente a la agonía de la ley de reforma laboral comenzó a debatirse la de desregulación de las aerolíneas -Airline Deregulation $A c t^{8}$ - que, finalmente, sería aprobada en octubre de 1978, y que originaría graves daños tanto a las empresas como a los sindicatos, anunciando ya la política sistemática de desregulaciones que emprendería el sucesor de Carter, Ronald Reagan.

El fracaso de este proyecto de reforma revelaba el cambio en la opinión que estaba en marcha, pero el verdadero punto de inflexión se iba a producir en los años ochenta con el gobierno de Reagan. En estos años se produjo una "radical transformación", en palabras de Osterman (1999: 5-6). Según este autor, a partir de entonces se produjo la retirada de los sindicatos, el gobierno redujo su papel en las políticas sobre el mercado de trabajo y la inseguridad económica fue creciente en torno a un amplio espectro de empleos. Además, la cultura empresarial y la actitud de los empleadores frente a los trabajadores también comenzaron a cambiar radicalmente.

\subsection{Presidencia de Ronald Reagan (1981-1989)}

La constitución de la Administración Ronald Reagan (1981-1989) supuso el punto de viraje fundamental porque fue el momento, 1981, en que las fuerzas económicas partidarias de un nuevo modelo de crecimiento y de funcionamiento alternativo se hicieron con las riendas del poder político, dispuestas a romper con el consenso social, ignorando el compromiso político con el empleo, utilizando el desempleo como instrumento disuasorio contra los salarios y desembarazándose de la política social instituida en los años sesenta, por una parte; eliminar las regulaciones que afectaban a sectores estratégicos como finanzas, energía, comunicaciones y transporte; minimizar la actividad fiscal del Estado y preferenciar unilateralmente la política monetaria como instrumentos de gestión pública de la economía, por otra; además de

7 Labor Law Reform, Message to the Congress Transmitting Proposed Legislation, July 18, 1977.

8 Public Law 95-504, 95 ${ }^{\text {th }}$ Congress Airline Desregulation Act of 1978, Oct. 24, 1978. 
propugnar la desaparición de los obstáculos internacionales que limitaban la movilidad del capital (Palazuelos, 2010, pp. 93-94). Opina Chomsky que "con el fervientemente antiobrero Gobierno de Reagan" los ataques a los sindicatos recuperaron "su pleno apogeo". "El presidente Reagan le dejó claro al mundo de los negocios que no se impondrían las leyes que protegen los derechos laborales, nunca muy fuertes" (Chomsky, 2016: 183).

Uno de los frentes de ataque de Reagan fueron los sindicatos y los profesionales. Reagan se mostró implacable y contundente con la Organización de Controladores Profesionales del Tráfico Aéreo (PATCO) en la prolongada huelga que protagonizaron en 1981. Esta actitud anunciaba el "asalto en toda regla a los derechos de la fuerza de trabajo", según Harvey (2007, p. 30), en el preciso momento en que la recesión inducida por la política de Volcker estaba generando elevados niveles de desempleo. Hay que tener en cuenta que PATCO era un sindicato de cuello blanco con el carácter de asociación de profesionales cualificados, siendo más un icono de la clase media que del sindicalismo obrero.

Reagan impulsó una política que conduciría a un colapso del movimiento sindical en los Estados Unidos, entre 1980 y 1990, que "no tiene ningún parangón en ningún país occidental [...] viniendo a pagar así los sindicatos la renuncia a su participación en la política que habían hecho después de la Segunda Guerra Mundial, reduciendo su actividad a una limitada defensa de los intereses profesionales del grupo, y colaborando en la Guerra Fría, tanto en el interior como en la escena internacional, en la lucha contra cualquier manifestación de izquierdismo y contra cualquier planteamiento en términos de conciencia de clase”, según Fontana (2011: 618). El declive de la densidad sindical comenzó con Reagan y durante los años de su mandado fue particularmente importante.

En palabras de Álvarez et al., él "ya demostró cuál iba a ser su actitud ante los sindicatos cuando en 1981 sustituyó a la totalidad de los controladores aéreos que, en ese momento, se habían declarado en huelga" (2009: 215). Estos mismos autores cuentan que, desde los años ochenta, "la principal vía para impedir la labor de los sindicatos ha sido la composición del National Labor Relations Board (NLRB), que es el organismo que prevé la National Labor Relations Act (NLRA) como encargado de la supervisión del mercado de trabajo. Su composición varía en función de lo que decida el gobierno de turno, y desde aquellos años, los sucesivos gobiernos han tendido a nombrar en él a miembros favorables a las empresas como forma de reducir el poder de los trabajadores" (Álvarez et al., 2009: 219-220). Además, "el número de 
conflictos laborales (tanto huelgas como cierres patronales) que afectaron, al menos, a 1.000 trabajadores, bajó de 235 en 1979 [...] a 20 en 2006 [...], lo que puede explicarse tanto por la menor presencia de los sindicatos como por las dificultades institucionales para que estos ejerzan su labor. Solamente entre 1979 y 1984, el número de este tipo de conflictos ya había bajado hasta 62" (Álvarez et al., 2009: 215). En relación con la caída de la actividad huelguística, según los datos aportados por Levy y Temin (2007: 37), en la década de 1970, un promedio del 1,7 por ciento de la fuerza de trabajo participaba anualmente en paros laborales; en la década de 1980, esta tasa se redujo en más de dos tercios al 0,5 por ciento. A pesar de que el número de quejas sindicales sobre prácticas laborales injustas estaba en aumento, la politización de la NLRB redujo drásticamente el retorno a los paros laborales y desanimó a los trabajadores a intentarlos, apuntan Flynn (2000) y Roomkin (1981).

En suma, el apoyo de la política económica de Reagan al planteamiento monetarista de Volcker y su lucha contra la inflación que se logró controlar, pasando del 8,9\% en 1981 a tan sólo el 3,8\% dos años más tarde-, y su posterior política monetaria restrictiva, junto a los recortes impositivos en el lado de la oferta y la reducción de las tasas marginales de impuestos a los contribuyentes de altos ingresos del 70\% a alrededor del $28 \%$, en 1986 y el despido de los controladores aéreos y la consecuente descertificación del sindicato de controladores, uno de los pocos sindicatos que apoyaban a Reagan, debilitaron la posición de los trabajadores. Y es que la política monetaria restrictiva implementada por Volcker desempeñó, sin duda, un importante papel en el control de la inflación, aunque otro de los factores explicativos de tal descenso de la inflación fue la importante apreciación del dólar acaecida hasta 1985, como consecuencia de la mezcla de dicha política monetaria contractiva con la expansiva política fiscal (reducción de impuestos e incremento del gasto público). Esta fuerte subida del dólar conllevó un incremento del déficit de la balanza comercial al perder competitividad las empresas norteamericanas ante el encarecimiento en el exterior de los productos estadounidenses. Se produjo de esta manera una considerable bajada en la rentabilidad de la industria — salvo la armamentística que siguió produciendo muchos beneficios-, lo que influyó decisivamente en la crispación del clima social (Díez Espinosa et al., 2006: 458).

Apuntan Panicht y Gindin (2015), en este contexto, que el «shock Vlocker», como se denominó al draconiano aumento por parte de la Fed de los tipos de interés, estaba dirigido a establecer un permanente parámetro antiinflación que garantizara que el dólar, respaldado por los 
bonos del Tesoro, resultara un anclaje de confianza para las finanzas internacionales. Ello fue acompañado por un giro neoliberal más amplio en Estados Unidos y por su posterior universalización, cuando muchos Estados se abrieron al libre comercio y al libre movimiento del capital y pasaron a estimular la propagación y profundización de las relaciones sociales capitalistas. De este modo, entienden estos autores que "el neoliberalismo era esencialmente una respuesta política a las ganancias democráticas que anteriormente habían logrado las clases trabajadoras y que, desde la perspectiva capitalista, se habían vuelto barreras para la acumulación”.

Las consecuencias de la política de Reagan fueron dramáticas para muchos estadounidenses, pues en los años de su presidencia el desempleo creció, sobre todo en los primeros años. En 1982 hubo 30 millones de personas sin trabajo durante todo el año o parte del mismo. Una consecuencia de ello fue que más de 16 millones de norteamericanos se quedaron sin el seguro médico, que a menudo iba asociado al hecho de tener empleo. Ello provocó un aumento de las personas definidas como pobres, según el umbral oficial de pobreza establecido por el gobierno. No hay que olvidar que la administración de Reagan permitió que el salario mínimo alcanzara un mínimo histórico en el año 1989, solamente superado ligeramente después en los años 2005 y 2006 (cuadro 1).

$\mathrm{Al}$ mismo tiempo, en aquellos años se produjo una disminución del porcentaje de la renta total poseído por el $80 \%$ inferior de las familias, que coincidió con una disminución absoluta - y no sólo proporcionalpara el 60\% inferior de los hogares entre 1979-1989, mientras que el 1\% superior veía sus ingresos aumentados en un $87 \%$. Lee, entre otros, argumenta que la caída del valor del salario mínimo fue un determinante significativo de la desigualdad durante este período (Lee, 1999: 977). También Autor et al. (2008, p. 301) resaltaban, desde una perspectiva más amplia, que el aumento de la desigualdad reflejaba un cambio en el régimen del cual el salario mínimo decreciente era parte. A finales del mandato de Reagan, la diferencia entre ricos y pobres en los Estados Unidos había aumentado de forma dramática. Este aumento de la desigualdad económica fue concomitante con la mayor dispersión salarial, puesta de relieve por el aumento progresivo y constante del cociente D9/D1. Mientras que en 1980 los altos ejecutivos de las corporaciones ganaban 40 veces más de lo que ganaba el obrero medio, en 1989 ganaban 93 veces más (Zinn, 2001: 421). 
Cuadro 1. Evolución del salario mínimo real, 1973-2013 (en dólares estadounidenses constantes de 2015 y porcentajes de variación).

\begin{tabular}{|c|c|c|c|c|c|}
\hline Año & $\begin{array}{c}\text { Dólares } \\
\text { USA } 2015\end{array}$ & $\begin{array}{c}\% \\
\text { Variación } \\
\end{array}$ & Año & $\begin{array}{c}\text { Dólares } \\
\text { USA } 2015 \\
\end{array}$ & $\begin{array}{c}\% \\
\text { Variación }\end{array}$ \\
\hline 1973 & $17.765,6$ & $\ldots$ & 1994 & $14.135,5$ & $-2,54 \%$ \\
\hline 1974 & $18.664,9$ & $+5,06 \%$ & 1995 & $13.749,7$ & $-2,73 \%$ \\
\hline 1975 & $19.237,4$ & $+3,07 \%$ & 1996 & $13.751,1$ & $+0,01 \%$ \\
\hline 1976 & $19.924,8$ & $+3,57 \%$ & 1997 & $14.997,7$ & $+9,07 \%$ \\
\hline 1977 & $18.708,5$ & $-6,10 \%$ & 1998 & $15.575,4$ & $+3,85 \%$ \\
\hline 1978 & $20.027,1$ & $+7,05 \%$ & 1999 & $15.241,9$ & $-2,14 \%$ \\
\hline 1979 & $19.699,4$ & $-1,64 \%$ & 2000 & $14.744,1$ & $-3,27 \%$ \\
\hline 1980 & $18.545,3$ & $-5,86 \%$ & 2001 & $14.338,8$ & $-2,75 \%$ \\
\hline 1981 & $18.163,7$ & $-2,06 \%$ & 2002 & $14.114,9$ & $-1,56 \%$ \\
\hline 1982 & $17.114,3$ & $-5,78 \%$ & 2003 & $13.801,6$ & $-2,22 \%$ \\
\hline 1983 & $16.581,7$ & $-3,11 \%$ & 2004 & $13.441,8$ & $-2,61 \%$ \\
\hline 1984 & $15.898,0$ & $-4,12 \%$ & 2005 & $13.000,7$ & $-3,28 \%$ \\
\hline 1985 & $15.353,6$ & $-3,42 \%$ & 2006 & $12.594,4$ & $-3,13 \%$ \\
\hline 1986 & $15.067,6$ & $-1,86 \%$ & 2007 & $12.974,4$ & $+3,02 \%$ \\
\hline 1987 & $14.535,0$ & $-3,53 \%$ & 2008 & $14.097,6$ & $+8,66 \%$ \\
\hline 1988 & $13.965,5$ & $-3,92 \%$ & 2009 & $15.756,4$ & $+11,77 \%$ \\
\hline 1989 & $13.322,4$ & $-4,60 \%$ & 2010 & $16.391,3$ & $+4,03 \%$ \\
\hline 1990 & $13.913,5$ & $+4,44 \%$ & 2011 & $15.889,7$ & $-3,06 \%$ \\
\hline 1991 & $14.977,2$ & $+7,65 \%$ & 2012 & $15.567,6$ & $-2,03 \%$ \\
\hline 1992 & $14.932,2$ & $-0,30 \%$ & 2013 & $15.342,8$ & $-1,44 \%$ \\
\hline 1993 & $14.504,0$ & $-2,87 \%$ & & & \\
\hline
\end{tabular}

Fuente: ORganization For ECONOMIC COOPERATION AND DEVELOPMENT (OECD), Estadísticas del Empleo y del Mercado de Trabajo - Salarios mínimos reales. Disponible en: http://stats.oecd.org/viewhtml.aspx?datasetcode=RMW\&lang=en\#, consulta realizada el $10 \mathrm{de}$ agosto de 2017. 


\subsection{Presidencia de George H. W. Bush (1989-1993)}

Los años de la presidencia de George H. W. Bush (1989-1993), estuvieron marcados por un acelerado deterioro de la situación económica, especialmente a partir de 1990, que provocó el estancamiento y la pérdida de poder adquisitivo del estadounidense medio, afectando además a los profesionales y directivos empresariales (Díez Espinosa et al., 2006: 461). El aumento de impuestos del presidente, que se había comprometido a congelar la fiscalidad de las clases medias, impactó en esta pérdida de la capacidad adquisitiva de los estadounidenses. Durante estos años de presidencia de Bush, más dedicado a los asuntos exteriores y la consecuente desatención a los problemas internos, el desempleo creció en proporciones inusuales. Todo ello provocó un aumento de la desigualdad y la pobreza, a lo que se unieron las bancarrotas, tanto empresariales como personales.

En el ámbito laboral, dos actuaciones cabe resaltar durante este período. En primer lugar, la firma por Bush de las enmiendas a la FLSA, en noviembre de 1989 , que elevarían el salario mínimo a $4,25 \$$ por hora a partir de abril de 1991. Ello supuso una victoria significativa para Bush sobre los demócratas del Congreso, quienes en la primavera de 1989 habían aprobado un proyecto de ley, que el presidente vetó el 13 de junio, elevando el salario mínimo a $4.55 \$$. En segundo lugar, y quizá el aspecto más notable de sus años de presidencia, fue que Bush iba a ser el primer presidente en intentar, al menos, nombrar a un gerente del NLRB con un sustancial background sindical, nominando a Donald Rodgers, un funcionario del Departamento del Trabajo que había pasado más de veinte años en tres diferentes administraciones republicanas. Sin embargo, esta designación fue rechazada por el Comité Nacional de Derecho al Trabajo (National Right to Work Committee), quedando pendiente de aprobación, hasta que surgieron denuncias de que Rodgers había presionado a la NLBR para que resolviera un caso pendiente mientras trabajaba como asistente de la Casa Blanca (Flynn, 2000: 13931394).

\subsection{Presidencias de Bill Clinton (1993-2001)}

Las dos presidencias de Bill Clinton (1993-2001) fueron en los Estados Unidos un período de prosperidad — matizada por que los logros económicos de su "nueva economía" estuvieron relacionados en gran medida con el extraordinario rendimiento del mercado de valores, mediante movimientos especulativos como el que suscitaron las 
compañías relacionadas con Internet y las nuevas tecnologías (dot.com), que generó una estructura financiera muy frágil— favorecida, además, por la circunstancia de que no se produjera ninguna recesión durante aquellos años.

El discurso sobre la "globalización" y el reforzamiento de la actividad financiera manifestado ya en el decenio de 1980, que produjo una "financiarizacion" de todo, fueron los rasgos básicos del contexto en la etapa de Clinton. En relación con las políticas de Clinton, podría decirse que su administración se caracterizó fundamentalmente por la desregulación de los mercados financieros, la defensa a ultranza y puesta en práctica del libre comercio, las reducciones en el gasto público a todos los niveles - también el gasto público social-, en línea con su prioridad macroeconómica más amplia de reducir el déficit estadounidense y algunos suaves e incoherentes esfuerzos por regular el mercado de trabajo. Sostienen Álvarez Peralta y Buendía que durante el gobierno de Clinton "se ha practicado una durísima política laboral contra las conquistas históricas del trabajo, en un intento por ganar competitividad internacional, mejorar la productividad y reforzar los incrementos de las ganancias empresariales" (Álvarez Peralta y Buendía, 2004: 5).

Estas bases de las políticas de Clinton se enmarcaron en los planteamientos del neoliberalismo. De hecho, fue durante su presidencia cuando comenzó a circular la expresión "Consenso de Washington" para designar las posiciones comunes de la administración estadounidense, el Fondo Monetario Internacional (FMI) y el Banco Mundial (BM), que incluían, entre otras, el libre comercio, una participación menor del Estado en la economía y la desregulación de los mercados financieros.

Todos estos ejes de la política de Clinton tuvieron impacto en el ámbito laboral de una manera más o menos directa. Así, dentro del contexto de su política comercial en defensa del libre comercio, tras una intensa campaña, Clinton logró la entrada en vigor del Tratado de Libre Comercio de América del Norte/North American Free Trade Agreement (TLCAN/NAFTA) en 1994, que había negociado su antecesor ${ }^{10}$, y poner

\footnotetext{
9 No debe confundirse el contenido académico o científico que envuelve al término "globalización" con el uso político, a modo de eslogan, con el que fue empleado por Clinton. ${ }^{10}$ Formalmente, las negociaciones trilaterales se iniciaron el 5 de febrero de 1991, cuando los presidentes Carlos Salinas de Gortari y George Bush y el primer ministro Brian Mulroney anunciaron formalmente el inicio de las negociaciones de un nuevo tratado. Poco después, el 27 de febrero de 1991, Estados Unidos contó con la aprobación del Congreso, por la vía rápida [La vía rápida — fast track - suponía que el presidente estadounidense ponía a disposición del Congreso el texto del NAFTA/TLCAN para su aprobación o rechazo en una sesión, sin posibilidad de enmienda].
} 
en marcha el Área de Libre Comercio de las Américas (ALCA) también en 1994. El TLCAN produjo efectos adversos sobre los trabajadores de los Estados Unidos.

De acuerdo con Faux (2008), el TLCAN/NAFTA trajo consigo el estancamiento de los salarios y la redistribución hacia arriba del ingreso, la riqueza y el poder político, además de cuatro efectos adversos sobre los trabajadores de EE.UU. El primero, cuando la producción se trasladó a México, causó la pérdida de unos 700 mil puestos de trabajo, sobre todo en California, Texas, Michigan y otros estados donde se concentraban las manufacturas, y a los cuales llegaban muchos inmigrantes desde México. El segundo es que el TLCAN fortaleció la capacidad de los empleadores estadounidenses para obligar a los trabajadores a aceptar salarios y prestaciones más bajos. El tercero, el efecto destructivo del TLCAN en la agricultura y en pequeñas empresas mexicanas dislocó a varios millones de trabajadores mexicanos y sus familias, y fue una razón preponderante del espectacular aumento de indocumentados en el mercado laboral de Estados Unidos. El cuarto, y más importante, según este autor es que el TLCAN fue el modelo para las reglas de la nueva economía mundial, según el cual los beneficios se trasladan al capital y los costes al trabajo. La clase gobernante de Estados Unidos -en alianza con las élites financieras de sus socios comerciales- aplicó los principios del TLCAN a la OMC y a las políticas del BM y del FMI, así como al acuerdo que permitió que los empleadores de la gran oferta de trabajo de bajos salarios de China accedieran a los mercados de Estados Unidos a cambio de que las corporaciones multinacionales estadounidenses tuvieran derecho a invertir en su país.

Resulta bastante complicado estimar de una manera precisa el impacto del TLCAN/NAFTA sobre los trabajadores o los salarios en Estados Unidos, pero sí quedaron claros los argumentos de la administración Clinton, recogidos en el Economic Report of the President (1998), en el sentido de que el comercio no era sustancialmente responsable ni del largo estancamiento de los salarios de la mayoría de los trabajadores estadounidenses ni de las diferencias cada vez mayores entre los salarios más altos y los más bajos. La creciente desigualdad en las retribuciones de la fuerza de trabajo las atribuía al "sesgo hacia puestos de trabajo más especializados inducido por el cambio tecnológico", ya que la introducción de nuevos procesos basados en el uso de ordenadores creaba estímulos salariales para los trabajadores capaces de hacerlos funcionar, al tiempo que deprimía los ingresos de los 
trabajadores no informatizados ${ }^{11}$. Howell (1999: 54-86) demostró los errores básicos de este planteamiento, evidenciando que la creciente desigualdad salarial reflejaba más los cambios sociales e institucionales que los tecnológicos; en particular el continuo debilitamiento de los sindicatos y la creciente hostilidad de las leyes laborales hacia las aspiraciones de los trabajadores (Howell, 1999: 81).

De una manera más concreta, refiriéndonos a las medidas adoptadas por Clinton en relación al mercado laboral, cabe resaltar que aceptó, en 1996-1997, un aumento en dos fases del salario mínimo desde 4,25 dólares por hora - hasta 4,75 dólares en octubre de 1996 y hasta 5,15 en septiembre de 199712 — nivel en el que permaneció hasta el final de su presidencia. Sin embargo, ese modesto incremento no sirvió apenas para invertir la caída en picado del valor real del salario mínimo. En 1996, el valor real de los 4,25 dólares de entonces estaba más del 40\% por debajo de su poder de compra en 1968. Con el nuevo salario mínimo de 5,15 dólares, todavía quedaba éste un $30 \%$ por debajo de su valor real en 1968, mientras que la economía se había hecho un $81 \%$ más productiva entre 1968 y 2000 (Pollin y Luce, 1998: 53). Los partidarios de Clinton argumentaban que el declive del salario mínimo se veía compensado por un aumento sustancial de las dotaciones derivadas del Earned Income Tax Credit (EITC), una especie de renta básica.

Otro de los hitos de la administración Clinton fue la presentación de la Ley sobre Permisos por Cuestiones Familiares o de Salud (The Family and Medical Leave Act ${ }^{13}$ ), de febrero de 1993. La Ley obligaba a los patronos con cincuenta o más empleados en un área de setenta y cinco millas a conceder, a quienes hubieran trabajado un mínimo de 1.250 horas en el año anterior, doce semanas de permiso pagado por año, ya fuera por problemas de salud, por el nacimiento o la adopción de un niño, o para cuidar a un miembro de su familia. Los límites exactos de esas razones se definían de una manera bastante imprecisa, así como las condiciones que podían imponer los patronos. Así, por ejemplo, no dejaba claro si las empresas podían exigir a sus empleados que utilizasen sus días de vacaciones o por enfermedad antes de hacer uso de la ley (Pollin, 2000: 18-19 y 2005: 34).

\footnotetext{
${ }^{11}$ Economic Report of the President (1998) [Administration of William J. Clinton]. 12 Visto en: United States DePartment OF LABor, "History of Changes to the Minimum Wage Law". [Disponible en: https://www.dol.gov/whd/minwage/coverage.htm, consultado el 20 de febrero de 2018].

13 Public Law 103-3, 103 ${ }^{\mathrm{d}}$ Congress, An Act to grant family and temporary medical leave under certain circumstances, Enacted February 5, 1993.
} 
En otro ámbito, en el área de la formación laboral, proclamada como eje central de la promesa de Clinton de «Put the People First», la Ley de Inversión en Fuerza de Trabajo (The Workforce Investment Act ${ }^{14}$ ), de agosto de 1998, fusionó los aproximadamente cuarenta programas de formación federales, introduciendo bonos para que los trabajadores pagasen privadamente sus cursillos, y creando una base de datos sobre puestos de trabajo para todo el país, a través de Centros One-Stop Career $^{15}$.

En marzo de 1993, Clinton presentó una Ley de Sustitución de Huelguistas (Striker Replacement Act), que habría impedido a las empresas reemplazar con carácter definitivo a los huelguistas en conflictos sobre condiciones de trabajo (las sustituciones temporales y las huelgas por reivindicaciones salariales no se veían afectadas). La Ley no fue aprobada porque la administración Clinton no hizo apenas esfuerzos para conseguir apoyos a favor de la Ley. Finalmente, la Ley consiguió menos votos en el Senado que un proyecto similar de Bush. Sin embargo, y a juicio de Pollin, en lo que fue quizá el mejor ejemplo de la política de gestos de Clinton, éste firmó en marzo de 1995 una orden ejecutiva ${ }^{16}$ cancelando los contratos federales de más de 100.000 dólares a las empresas que habían sustituido definitivamente a obreros huelguistas. En un primer momento el Senado amenazó con bloquear esa iniciativa, pero al final desistió, persuadido quizá por insinuaciones de la Administración de que prácticamente ninguno de los grandes contratistas se vería afectado. En febrero de 1996 esa orden fue derogada por el Tribunal de Apelaciones de Washington, y la cuestión se desvaneció en el aire. Durante el año en que estuvo nominalmente en vigor, no se aplicó para cancelar ni un solo contrato (Pollin, 2005: 34).

Debe resaltarse, no obstante, que, en el otro lado de la balanza, Clinton vetó los recortes en la financiación del NLRB y de la Administración de Sanidad y Seguridad en el trabajo, y un proyecto de ley que habría legalizado los sindicatos de empresa. Igualmente, es de destacar que sus nombramientos en el NLRB fueron más favorables a la dirección de los sindicatos que antes, tal como señala Flynn (2000: 1394).

14 Public Law 105-220, 105 th Congress, An Act To consolidate, coordinate, and improve employment, training, literacy, and vocational rehabilitation programs in the United States, and for other purposes, Aug. 7, 1998.

15 Visto en: "Bill Clinton on Jobs". [Disponible en: http://www.ontheissues.org/2016/Bill_Clinton_-Jobs.htm, consultado el 11 de febrero de 2018].

16 Executive Order 12954 "Ensuring the Economical and Efficient Administration and Completion of Federal Government Contracts", March 8, 1995. 
A pesar de ello, durante la presidencia de Clinton la afiliación a los sindicatos, lejos de iniciar una recuperación, prosiguió su largo declive cayendo más aun en ese período, con un $12,4 \%$ del total de la fuerza de trabajo afiliada, casi cuatro puntos por debajo del 16,2\% al que había caído en 1988, el último año de la presidencia de Reagan.

Los resultados de estas reformas en el mercado laboral de Estados Unidos durante la presidencia de Clinton fueron desfavorables para los trabajadores estadounidenses. En efecto, pese al comportamiento macroeconómico relativamente notable —impulsado por la gigantesca expansión del mercado de valores, tal como se ha explicado ya- de la administración Clinton en comparación con los administraciones anteriores (cuadro 2), tanto los salarios medios de los trabajadores (no supervisores) como los ingresos de los que estaban en el decil más bajo de la distribución salarial, no sólo estaban muy por debajo de los correspondientes a las administraciones Nixon-Ford y Carter, sino incluso por debajo de los obtenidos en los años Reagan-Bush (cuadro 3).

Cuadro 2. Evolución del comportamiento de algunos indicadores macroeconómicos, 1961-2000 (porcentajes).

\begin{tabular}{|c|c|c|c|c|c|c|c|}
\hline \multirow{2}{*}{ Indicador } & \multirow{2}{*}{$\begin{array}{c}1961-1968 \\
\text { Kennedy- } \\
\text { Johnson }\end{array}$} & \multirow{2}{*}{$\begin{array}{l}\text { 1969-1976 } \\
\text { Nixon- } \\
\text { Ford }\end{array}$} & \multirow[t]{2}{*}{$\begin{array}{c}\text { 1977-1980 } \\
\text { Carter }\end{array}$} & \multirow{2}{*}{$\begin{array}{c}\text { 1981-1992 } \\
\text { Reagan- } \\
\text { Bush }\end{array}$} & \multicolumn{3}{|c|}{$\begin{array}{c}1993-2000 \\
\text { Clinton }\end{array}$} \\
\hline & & & & & $\begin{array}{c}1993- \\
1995 \\
\end{array}$ & $\begin{array}{c}1996- \\
2000\end{array}$ & $\begin{array}{l}1993- \\
2000\end{array}$ \\
\hline $\begin{array}{l}\text { Crecimiento } \\
\text { real del PIB }\end{array}$ & 4,8 & 2,7 & 3,4 & 2,9 & 3,1 & 4,1 & 3,7 \\
\hline $\begin{array}{l}\text { Aumento de la } \\
\text { productividad } \\
\text { (excepto sector } \\
\text { agrícola) }\end{array}$ & 3,4 & 2,1 & 0,5 & 1,7 & $0, .9$ & 2,5 & 1,9 \\
\hline $\begin{array}{l}\text { Tasa de } \\
\text { desempleo }\end{array}$ & 4,8 & 5,8 & 6,5 & 7,1 & 6,2 & 4,6 & 5,2 \\
\hline $\begin{array}{l}\text { Tasa de } \\
\text { inflación } \\
\text { (medida por el } \\
\text { IPC) }\end{array}$ & 2,0 & 6,4 & 9,7 & 4,6 & 2,8 & 2,5 & 2,6 \\
\hline
\end{tabular}

Fuente: Pollin, 2005, pp. 43-44. 
Cuadro 3. Evolución del comportamiento de algunos indicadores de salarios de los trabajadores y tasa de pobreza por períodos presidenciales, 1961-2000 (dólares de 1998 y porcentaje).

\begin{tabular}{lccccc}
\hline \multicolumn{1}{c}{ Indicador } & $\begin{array}{c}\mathbf{1 9 6 1 - 1 9 6 8} \\
\text { Kennedy- } \\
\text { Johnson }\end{array}$ & $\begin{array}{c}\mathbf{1 9 6 9 - 1 9 7 6} \\
\text { Nixon- } \\
\text { Ford }\end{array}$ & $\begin{array}{c}\mathbf{1 9 7 7 - 1 9 8 0} \\
\text { Carter }\end{array}$ & $\begin{array}{c}\mathbf{1 9 8 1 - 1 9 9 2} \\
\text { Reagan- } \\
\text { Bush }\end{array}$ & $\begin{array}{c}\mathbf{1 9 9 3 - 2 0 0 0} \\
\text { Clinton }\end{array}$ \\
\hline $\begin{array}{l}\text { Salario medio para trabajadores } \\
\text { no supervisores (en dólares de } \\
\text { 2001) }\end{array}$ & 13,6 & 15,14 & 15,03 & 13,91 & 13,6 \\
$\begin{array}{l}\text { Salario medio para el decil más } \\
\text { bajo (en dólares de 2001) }\end{array}$ & $\ldots$ & $6,67^{\text {a }}$ & 6,86 & 6,17 & 6,11 \\
$\begin{array}{l}\text { Relación entre los salarios del } \\
\text { decil más alto y el más bajo }\end{array}$ & $\ldots$ & $3,7^{\mathrm{a}}$ & 3,6 & 4,2 & 4,4 \\
\begin{tabular}{l} 
Tasa de pobreza individual (\%) \\
\hline
\end{tabular} & 17,6 & 11,9 & 11,9 & 14,0 & 13,2 \\
\hline
\end{tabular}

Fuente: Pollin, 2005, p. 51.

a Datos desde 1973.

Además, la desigualdad salarial, medida por la relación entre los deciles más alto y más bajo de la distribución salarial, se incrementó notablemente durante la presidencia de Clinton, incluso comparada con el apogeo republicano de la década de 1980. Sostiene Pollin, en este contexto, que durante la presidencia de Clinton "la distribución de la riqueza en los Estados Unidos se desequilibró más que en cualquier otro momento de los cuarenta años anteriores, poniendo el ejemplo de la relación entre el sueldo de un director ejecutivo y el de un trabajador medio, que pasó de 113 a 1 en 1991, con Bush padre, a 449 a 1, cuando Clinton dejó la presidencia en 2001" (Pollin, 2005: 18-19).

Por otro lado, cabe subrayar que cuando Clinton llegó a la Casa Blanca, el salario medio real estaba en un nivel bastante bajo y había una diferencia importante entre el salario real y el nivel de productividad. Durante su primer período presidencial, entre 1993 y 1996, no se produjo un aumento relevante del salario medio real, a pesar de que la productividad aumentó todos los años hasta 1996. Entre 1997 y 1999, el salario medio real aumentó vigorosamente tres años consecutivos. Por otra parte, el crecimiento de la productividad también se aceleró durante este período. Esto significó que los empresarios 
necesitaron más trabajadores para mantener el ritmo de expansión; de ahí que la capacidad de negociación de estos últimos aumentara. Sin embargo, como se ha expuesto, la administración Clinton no hizo prácticamente nada en cuanto a leyes laborales ni en el contexto político general para mejorar la capacidad de negociación de los trabajadores.

Tampoco se produjo ninguna reducción significativa de la pobreza bajo el mandato de Clinton, ni siquiera en comparación con el período Reagan-Bush, tal como evidencian los datos del cuadro 3. La disminución de la tasa de pobreza del $14,0 \%$ al $13,2 \%$ resulta mínima, si se tiene en cuenta que durante los gobiernos de Reagan y Bush se restringieron notablemente los esfuerzos antipobreza de la administración estadounidense. Además, como apunta Pollin, la situación empeoró para los oficialmente reconocidos como pobres, pues la «brecha de la pobreza», que mide la cantidad de dinero precisa para que todas las personas pobres alcancen exactamente el umbral oficial de pobreza, aumentó de 1.558 a 1.620 dólares (de 2001) entre 1993 y 1999 (Pollin, 2005: 54). Debe apuntarse igualmente que la reducción de la tasa de pobreza estuvo muy ligada a la situación del mercado laboral, algo pretendido deliberadamente por la administración Clinton, que redujo de forma considerable las subvenciones a los pobres sin trabajo.

A todos estos aspectos, hay que añadir, como aspecto central en la evolución del trabajo en Estados Unidos durante aquellos años, el aumento de la flexibilidad laboral. En este sentido, Álvarez Peralta y Buendía explican que las exigencias del capital financiero de rentabilidad a corto plazo estuvieron estrechamente vinculadas a los procesos de reorganización de la fuerza de trabajo tanto dentro de las empresas como fuera de ellas —básicamente la quiebra de la organización fordista en favor del modelo de producción flexible-. Este alto grado de flexibilidad se puso de manifiesto en que incluso los trabajadores indefinidos se vieron afectados por una política de despidos muy laxa. Por su parte, la inestabilidad en forma de frecuentes cambios de trabajo estuvo muy extendida (Álvarez Peralta y Buendía, 2004: 14-15). Por su parte, Levy y Temin apuntan que el potencial creciente para el trabajo offshore, junto con los avances en el trabajo computarizado, aumentaron las posibilidades de sustitución para los trabajadores de Estados Unidos. Sostienen estos autores que tanto la deslocalización como la amenaza de deslocalización sirvieron en aquellos años para debilitar aún más el poder de negociación y suprimir las demandas salariales (Levy y Temin, 2007: 38). Destacan estos autores cómo Bill Clinton, el "único presidente demócrata desde 1980, alentó el «Consenso de Washington» en sus posiciones centristas (2007: 37). 
En suma, pues, la evaluación de los efectos de las iniciativas de la administración Clinton sobre el mercado de trabajo tiene más aspectos negativos que positivos. Aunque su política pueda distinguirse de la de Bush o Reagan —está claro que de, una forma u otra, cualquier presidente demócrata ofrecerá más concesiones sociales que un oponente republicano de su misma generación, al igual que cualquier presidente republicano tendrá menos recato en movilizar el poder estatal a favor de los ricos-, se ha puesto de manifiesto que durante la presidencia de Nixon, por ejemplo, los salarios fueron más altos y hubo menos pobreza que con Clinton. Como se ha visto, el núcleo del programa de Clinton fue la integración económica global, con mínimas intervenciones para promover la equidad en el mercado de trabajo. Los gestos hacia los más desfavorecidos fueron insignificantes. Los salarios reales de la mayoría de los trabajadores presentaron un mayor nivel de dispersión, incrementándose la brecha entre los trabajadores mejor y peor remunerados, debido tanto a la pérdida de posiciones de los trabajadores peor pagados como al mayor crecimiento de los salarios de los trabajadores de remuneraciones altas. Además, la riqueza de los más pudientes se multiplicó. Y, mientras tanto, los mercados financieros recibieron un trato más generoso que el mercado de trabajo - las operaciones de rescate de los inversores durante las crisis que sacudieron México, el Este de Asia, y al fondo de inversiones Long-Term Capital Management (en realidad un hedge fund), la derogación de la ley GlassSteagall, dan cuenta de ello-. Está claro que Clinton puso los intereses de los mercados financieros en lo más alto de las prioridades de su administración (Pollin, 2005: 30).

Lógicamente, esto tuvo un impacto sobre la distribución del ingreso. Así, durante las dos presidencias de Bill Clinton (1993-2001), todos los grupos de ingresos más elevados mejoraron sus ingresos medios. De manera paralela, pero en sentido contrario, los quintiles de población hasta el $80 \%$ vieron disminuida su participación entre - 0,1 y $-0,5$ puntos porcentuales a favor del quintil superior de ingresos, que aumentó $+1,20$ puntos. La disminución mayor se situó en los quintiles centrales (cuadros 4 y 5$)$. 
Cuadro 4. Evolución de la distribución del ingreso por grupos de quintiles de población, 1973-2013 (porcentaje del total de ingresos).

\begin{tabular}{|c|c|c|c|c|c|c|}
\hline Años & $20 \%$ inferior & Segundo 20\% & Tercer $20 \%$ & Cuarto $20 \%$ & $20 \%$ superior & Total \\
\hline 1973 & 4,2 & 10,4 & 17,0 & 24,5 & 43,9 & 100,0 \\
\hline 1974 & 4,3 & 10,6 & 17,0 & 24,6 & 43,5 & 100,0 \\
\hline 1975 & 4,3 & 10,4 & 17,0 & 24,7 & 43,6 & 100,0 \\
\hline 1976 & 4,3 & 10,3 & 17,0 & 24,7 & 43,7 & 100,0 \\
\hline 1977 & 4,2 & 10,2 & 16,9 & 24,7 & 44,0 & 100,0 \\
\hline 1978 & 4,2 & 10,2 & 16,8 & 24,7 & 44,1 & 100,0 \\
\hline 1979 & 4,1 & 10,2 & 16,8 & 24,6 & 44,2 & 100,0 \\
\hline 1980 & 4,2 & 10,2 & 16,8 & 24,7 & 44,1 & 100,0 \\
\hline 1981 & 4,1 & 10,1 & 16,7 & 24,8 & 44,3 & 100,0 \\
\hline 1982 & 4,0 & 10,0 & 16,5 & 24,5 & 45,0 & 100,0 \\
\hline 1983 & 4,0 & 9,9 & 16,4 & 24,6 & 45,1 & 100,0 \\
\hline 1984 & 4,0 & 9,9 & 16,3 & 24,6 & 45,2 & 100,0 \\
\hline 1985 & 3,9 & 9,8 & 16,2 & 24,4 & 45,6 & 100,0 \\
\hline 1986 & 3,8 & 9,7 & 16,2 & 24,3 & 46,1 & 100,0 \\
\hline 1987 & 3,8 & 9,6 & 16,1 & 24,3 & 46,2 & 100,0 \\
\hline 1988 & 3,8 & 9,6 & 16,0 & 24,2 & 46,3 & 100,0 \\
\hline 1989 & 3,8 & 9,5 & 15,8 & 24,0 & 46,8 & 100,0 \\
\hline 1990 & 3,8 & 9,6 & 15,9 & 24,0 & 46,6 & 100,0 \\
\hline 1991 & 3,8 & 9,6 & 15,9 & 24,2 & 46,5 & 100,0 \\
\hline 1992 & 3,8 & 9,4 & 15,8 & 24,2 & 46,9 & 100,0 \\
\hline 1993 & 3,6 & 9,0 & 15,1 & 23,5 & 48,9 & 100,0 \\
\hline 1994 & 3,6 & 8,9 & 15,0 & 23,4 & 49,1 & 100,0 \\
\hline 1995 & 3,7 & 9,1 & 15,2 & 23,3 & 48,7 & 100,0 \\
\hline 1996 & 3,6 & 9,0 & 15,1 & 23,3 & 49,0 & 100,0 \\
\hline 1997 & 3,6 & 8,9 & 15,0 & 23,2 & 49,4 & 100,0 \\
\hline 1998 & 3,6 & 9,0 & 15,0 & 23,2 & 49,2 & 100,0 \\
\hline 1999 & 3,6 & 8,9 & 14,9 & 23,2 & 49,4 & 100,0 \\
\hline 2000 & 3,6 & 8,9 & 14,8 & 23,0 & 49,8 & 100,0 \\
\hline 2001 & 3,5 & 8,7 & 14,6 & 23,0 & 50,1 & 100,0 \\
\hline 2002 & 3,5 & 8,8 & 14,8 & 23,3 & 49,7 & 100,0 \\
\hline 2003 & 3,4 & 8,7 & 14,8 & 23,4 & 49,8 & 100,0 \\
\hline 2004 & 3,4 & 8,7 & 14,7 & 23,2 & 50,1 & 100,0 \\
\hline 2005 & 3,4 & 8,6 & 14,6 & 23,0 & 50,4 & 100,0 \\
\hline 2006 & 3,4 & 8,6 & 14,5 & 22,9 & 50,5 & 100,0 \\
\hline 2007 & 3,4 & 8,7 & 14,8 & 23,4 & 49,7 & 100,0 \\
\hline 2008 & 3,4 & 8,6 & 14,7 & 23,3 & 50,0 & 100,0 \\
\hline 2009 & 3,4 & 8,6 & 14,6 & 23,2 & 50,3 & 100,0 \\
\hline 2010 & 3,3 & 8,5 & 14,6 & 23,4 & 50,3 & 100,0 \\
\hline 2011 & 3,2 & 8,4 & 14,3 & 23,0 & 51,1 & 100,0 \\
\hline 2012 & 3,2 & 8,3 & 14,4 & 23,0 & 51,0 & 100,0 \\
\hline
\end{tabular}




\begin{tabular}{lllllll}
\hline 2013 & 3,2 & 8,4 & 14,4 & 23,0 & 51,0 & 100,0 \\
\hline Dif. & $\mathbf{- 1 , 0}$ & $\mathbf{- 2 , 0}$ & $\mathbf{- 2 , 6}$ & $\mathbf{- 1 , 5 0}$ & $\mathbf{+ 7 , 1 0}$ & \\
\hline
\end{tabular}

Fuente: United States Census Bureau, Historical Income Tables: Households-Table H2 Share of Aggregate Income Received by Each Fifth and Top 5 Percent of Households, All Races, 1967 to 2014. [Disponible en: https://www.census.gov/hhes/www/income/data/historical/household/, consultado el 26 de diciembre de 2017].

Cuadro 5. Estados Unidos: Evolución del ingreso familiar medio por grupos de quintiles de población, 1973-2013 (dólares de 2014).

\begin{tabular}{|c|c|c|c|c|c|c|}
\hline Años & $20 \%$ inferior & Segundo $20 \%$ & Tercer $20 \%$ & Cuarto $20 \%$ & $20 \%$ superior & Top $5 \%$ \\
\hline 1973 & 12.097 & 30.416 & 49.889 & 71.768 & 128.413 & 197.796 \\
\hline 1974 & 12.053 & 29.957 & 48.282 & 69.728 & 123.542 & 187.783 \\
\hline 1975 & 11.644 & 28.600 & 46.924 & 68.182 & 120.380 & 182.682 \\
\hline 1976 & 11.931 & 29.207 & 48.031 & 69.751 & 123.447 & 188.093 \\
\hline 1977 & 11.872 & 29.222 & 48.341 & 70.828 & 126.303 & 193.221 \\
\hline 1978 & 12.277 & 30.150 & 49.782 & 72.923 & 130.195 & 198.171 \\
\hline 1979 & 12.190 & 30.320 & 49.989 & 73.357 & 131.651 & 200.781 \\
\hline 1980 & 11.794 & 29.354 & 48.438 & 71.362 & 127.235 & 190.139 \\
\hline 1981 & 11.499 & 28.643 & 47.450 & 70.731 & 126.347 & 187.751 \\
\hline 1982 & 11.286 & 28.562 & 47.278 & 70.315 & 128.962 & 194.864 \\
\hline 1983 & 11.427 & 28.705 & 47.457 & 71.214 & 130.752 & 197.551 \\
\hline 1984 & 11.802 & 29.395 & 48.713 & 73.347 & 134.866 & 203.587 \\
\hline 1985 & 11.784 & 29.862 & 49.567 & 74.559 & 139.274 & 214.838 \\
\hline 1986 & 11.905 & 30.621 & 51.241 & 77.194 & 146.111 & 228.892 \\
\hline 1987 & 12.229 & 31.079 & 51.961 & 78.541 & 149.364 & 235.324 \\
\hline 1988 & 12.436 & 31.389 & 52.499 & 79.360 & 151.507 & 238.949 \\
\hline 1989 & 12,897 & 32.089 & 53.342 & 80.685 & 157.725 & 254.829 \\
\hline 1990 & 12.594 & 31.687 & 52.338 & 78.912 & 153.138 & 243.856 \\
\hline 1991 & 12.254 & 30.778 & 51.123 & 77.932 & 149.443 & 233.217 \\
\hline 1992 & 12.000 & 30.068 & 50.658 & 77.765 & 150.680 & 239.157 \\
\hline 1993 & 11.877 & 30.109 & 50.471 & 78.434 & 163.415 & 280.474 \\
\hline 1994 & 12.195 & 30.391 & 51.198 & 79.670 & 167.489 & 289.376 \\
\hline 1995 & 12.883 & 31.488 & 52.650 & 80.935 & 168.900 & 291.497 \\
\hline 1996 & 12.919 & 31.709 & 53.336 & 82.549 & 173.620 & 302.439 \\
\hline 1997 & 13.004 & 32.511 & 54.696 & 84.716 & 180.614 & 316-957 \\
\hline 1998 & 13.388 & 33.805 & 56.564 & 87.481 & 185.120 & 322.663 \\
\hline 1999 & 14.092 & 34.603 & 57.920 & 90.145 & 192.235 & 334.123 \\
\hline 2000 & 13.963 & 34.863 & 58.058 & 90.254 & 195.578 & 346.975 \\
\hline 2001 & 13.553 & 34.055 & 57.002 & 89.375 & 195.188 & 348.287 \\
\hline 2002 & 13.146 & 33.424 & 56.324 & 88.597 & 189.156 & 330.311 \\
\hline 2003 & 12.867 & 33.052 & 56.106 & 88.809 & 189.318 & 325.967 \\
\hline
\end{tabular}




\begin{tabular}{|c|c|c|c|c|c|c|}
\hline 2004 & 12.839 & 32.852 & 55.661 & 87.766 & 189.802 & 330.750 \\
\hline 2005 & 12.916 & 33.164 & 56.129 & 88.284 & 193.457 & 340.836 \\
\hline 2006 & 13.329 & 33.791 & 56.623 & 89.626 & 197.466 & 349.215 \\
\hline 2007 & 13.189 & 33.617 & 57.055 & 90.331 & 191.793 & 327.922 \\
\hline 2008 & 12.817 & 32.456 & 55.124 & 87.703 & 188.092 & 324.059 \\
\hline 2009 & 12.747 & 32.283 & 54.657 & 86.833 & 188.513 & 325.939 \\
\hline 2010 & 11.938 & 30.982 & 53.389 & 85.649 & 183.935 & 311.859 \\
\hline 2011 & 11.831 & 30.742 & 52.467 & 84.298 & 187.395 & 327.846 \\
\hline 2012 & 11.848 & 30.620 & 52.772 & 84.654 & 187.568 & 327.953 \\
\hline 2013 & 11.841 & 31.008 & 53.178 & 84.885 & 188.236 & 327.618 \\
\hline \multirow{2}{*}{$\begin{array}{l}\text { Dife- } \\
\text { rencia }\end{array}$} & -256 & +592 & +3.289 & +13.117 & +59.820 & +129.822 \\
\hline & $-2,12 \%$ & $+1,95 \%$ & $+6,59 \%$ & $+18,28 \%$ & $+46,58 \%$ & $+65,63 \%$ \\
\hline
\end{tabular}

Fuente: United States Census Bureau, Historical Income Tables: Households-Table H3 Mean Household Income Received by Each Fifth and Top 5 Percent, All Races, 1967 to 2014. [Disponible en: https://www.census.gov/hhes/www/income/data/historical/household/, consulta realizada el 26 de diciembre de 2017].

\subsection{Presidencia de George W. Bush (2001-2009)}

El presidente George W. Bush (2001-2009) siguió también una agenda esencialmente neoliberal, puesta de manifiesto en los recortes sustanciales de impuestos a los ricos y el recorte de los fondos para financiar los programas sociales estatales. Afirma Pollin categóricamente que "desde su entrada en funciones, la Administración de Bush emprendió una agenda inconmovible que favorecía a los grandes negocios y a los ricos" (Pollin, 2005: 14).

Entre las escasas iniciativas llevadas a cabo por la administración Bush en el ámbito laboral, cabe referirse a la Ley de creación de empleo y asistencia al trabajador de 2002 (Job Creation and Workers Assistance Act of 2002-JCWAA ${ }^{17}$ ), promulgada después de los ataques terroristas del 11 de septiembre de 2001. La ley contenía exenciones impositivas para las empresas del Bajo Manhattan y a nivel nacional que habían sido afectadas por los ataques terroristas. Contenía también la Ley varias disposiciones relativas a las pensiones y otras prestaciones para los trabajadores. La Ley pretendía alentar a la economía para salir de la recesión en la que se encontraba desde antes de que Bush iniciara su presidencia, como consecuencia de los graves desequilibrios financieros que se habían ido acumulando desde la década de 1990.

17 Public Law 107-147, 107 $7^{\text {th }}$ Congress, An Act to provide tax incentives for economic recovery, Mar. 9, 2002. 
En realidad, el presidente Bush se dedicó más a la negociación y firma de nuevos acuerdos comerciales basados en el TLCAN/NAFTA con docenas de países en todo el mundo. Estos tratados no tenían fuerza ejecutiva protectora para los derechos de los trabajadores. Así, en septiembre de 2001, se firmó el Tratado de Libre Comercio de JordaniaEstados Unidos; en septiembre de 2003, el de Chile y el de Singapur; en julio de 2004, el de Marruecos, en agosto, el de Australia; en agosto de 2005, el de Centroamérica y República Dominicana; y en enero de 2006, el de Baréin. La AFL-CIO acusaba a la administración Bush de negarse a hacer cumplir las disposiciones sobre los derechos de los trabajadores que existían en los convenios comerciales, además de permitir que otros países violasen las reglas de comercio internacional con impunidad, negándose a usar agresivamente las herramientas de resolución de conflictos y aplicación para hacer valer los derechos de los Estados Unidos y proteger los intereses del trabajador estadounidense. Además, se reprochaba que, a través de recortes presupuestarios e implementaciones fracasadas, la administración Bush hubiera modificado programas gubernamentales para trabajadores desplazados y derechos de los trabajadores en el extranjero (AFL-CIO, 2004: 1-2).

En suma, acusaban a la administración Bush de que, en lugar de crear nuevos empleos y defender los intereses de los trabajadores de EE.UU., la administración Bush había elegido apoyar activamente las políticas que empeoraban el déficit comercial, someter a los trabajadores a prácticas comerciales desleales y recompensar a las empresas por mudar empleos al extranjero. El resultado de estas elecciones erróneas y fundamentalmente equivocadas había sido la pérdida de cientos de miles de puestos de trabajo (AFL-CIO, 2004, p. 8). Solo en el sector manufacturero, según cálculos del Economic Policy Institute (EPI), entre 2000 y 2003 se perdieron 935 mil puestos de trabajo (AFL-CIO, 2004: 2).

Los partidarios de Bush, en cambio, sostenían que la administración de Bush había adoptado un "enfoque reflexivo y mesurado de las cuestiones laborales" y que "fue efectiva en reformar y hacer cumplir las leyes del mercado de trabajo donde más se necesitaban esos esfuerzos" (Kilberg et al., 2009).

Uno de los hitos de la administración Bush que debe destacarse fue la Ley del salario mínimo justo de 2007 (Fair Minimum Wage Act of 200718), que introdujo una enmienda en la FLSA de 1938 para elevar gradualmente el salario mínimo federal de 5,15 dólares por hora a 7,25

${ }^{18}$ H.R. 2, $110^{\text {th }}$ Congress, To amend the Fair Labor Standards Act of 1938 to provide for an increase in the Federal minimum wage, Feb. 1, 2007. 
dólares por hora. La ley se promulgó como parte de la Ley de Preparación de Tropas, Cuidado de Veteranos, Recuperación de Katrina y Responsabilidad de Irak, promulgada el 25 de mayo de 2007 (U.S. Troop Readiness, Veteneran' Care, Katrina Recovery, and Iraq Accountability Appropriations Act, 2007). El aumento del salario mínimo se contempló en tres fases sucesivas: a 5,85 dólares por hora, sesenta días después de la promulgación de la Ley (24-julio-2007); a 6,55 dólares por hora, doce meses después (24-julio-2008); y, finalmente, a 7,25 dólares por hora doce meses después (24-julio-2009). Esta elevación del salario mínimo, que no se había realizado desde diez años antes, fue objeto de defensa por parte de algunos y de críticas por parte de otros. Argumentaban los primeros que la subida del salario mínimo era necesaria y que el salario mínimo era un "suelo" salarial básico, mientras que los críticos sostenían que los aumentos en el salario mínimo podían hacer que los empleadores respondiesen buscando reducir los costes laborales. Según el EPI, alrededor de trece millones de trabajadores o el 10\% de la fuerza laboral del país se beneficiarían de la subida. De esos trece millones, 5,6 millones se verían directamente afectados, mientras que 7,4 millones de trabajadores con salarios bajos verían el efecto indirecto en sus salarios (Zappone, 2007).

\subsection{Presidencia de Barack Obama (2009-2017)}

El legado del presidente de Barack Obama (2009-2017) en el ámbito del mercado de trabajo incluyó varias iniciativas que fueron promulgadas a través de órdenes ejecutivas (executive orders), que tenían fuerza de ley, pero no la aprobación del Congreso. De esta forma, Obama evitó el obstruccionismo del Congreso, controlado por los republicanos, pero no el riesgo de que estas reformas logradas mediante órdenes ejecutivas pudieran ser revertidas o revocadas por un futuro presidente, sobre todo si éste fuera republicano, porque los republicanos se han opuesto sistemáticamente a las reformas a favor de los trabajadores estadounidenses.

El contexto económico en el que Obama asumió la presidencia era especialmente grave. Hasta febrero de 2009, el primer mes completo de la administración Obama, la economía había estado en recesión durante trece meses y la gravedad de la crisis económica se estaba acelerando. En los seis meses anteriores, se habían perdido 650 mil empleos cada mes en promedio, según el EPI (Bivens, 2017). 
Ya en sus primeros cien días, Obama firmó su primera ley, la Lilly Ledbetter Fair Pay Act of 200919, que revirtió la decisión del Tribunal Supremo de Ledbetter v. Goodyear Tire \& Rubber Co. Inc., con respecto al período de limitaciones para el pago de las reclamaciones por discriminación salarial de género. La Ley se llamó así por la Sra. Ledbetter, una mujer de Alabama que al final de una carrera de diecinueve años como supervisora en una fábrica de neumáticos se quejó de que le habían pagado menos que a los hombres, cuya historia había contado Obama una y otra vez en la campaña por la Casa Blanca.

Además de esta Ley sobre la igualdad salarial, Obama adoptó medidas ejecutivas para exigir a los contratistas del gobierno que ofrecieran el mismo salario, a la vez que creó vías para una mayor transparencia por parte de los empleadores, que deberían divulgar los salarios totales y las horas trabajadas en los informes conocidos como Employer Information Report-EEO-1 para identificar mejor la discriminación salarial ${ }^{20}$.

Por otro lado, la administración de Obama reguló sobre una variedad de otros temas relacionados con el mercado de trabajo, que los empleadores denunciaron como demasiado agresivos. Así, se exigió a los empleadores que informaran de posibles situaciones en las que los asesores legales intentaran persuadir a los empleados durante las campañas de sindicalización; se exigió asimismo a los empleadores que presentasen informes sobre lesiones y enfermedades en el lugar de trabajo, que revelaran violaciones previas de las leyes laborales federales, etc. Igualmente, se regularon una serie de normas para los contratistas federales, que aumentaron el salario mínimo a más de diez dólares ${ }^{21}$ a la vez que concedieron permisos por enfermedad con sueldo y proporcionaron protecciones más fuertes para sus empleados LGBT.

Bien es cierto que, como se ha dicho, pocos de estos avances logrados se aprobaron por el Congreso, controlado por los republicanos durante la mayor parte del tiempo de la presidencia de Obama. Por ello, algunos analistas valoran como fracaso sus esfuerzos por expandir las

19 Public Law 111-2, $111^{\text {th }}$ Congress An Act To amend title VII of the Civil Rights Act of 1964 and the Age Discrimination in Employment Act of 1967, and to modify the operation of the Americans with Disabilities Act of 1990 and the Rehabilitation Act of 1973, to clarify that a discriminatory compensation decision or other practice that is unlawful under such Acts occurs each time compensation is paid pursuant to the discriminatory compensation decision or other practice, and for other purposes. Jan, 29, 2009.

${ }^{20}$ Executive Order 13665 "Non-Retaliation for Disclosure of Compensation Information", April 08, 2014.

${ }^{21}$ Executive Order 13658 "Establishing a Minimum Wage for Contrators", February 12, 2014. 
leyes laborales, al confiar casi exclusivamente en el poder ejecutivo (Gurriere, 2017).

Uno de los mayores fracasos de la administración Obama en el contexto laboral fue la imposibilidad de cumplir con su promesa de campaña de 2008 de impulsar una legislación que hubiera facilitado la sindicación de los trabajadores, pero ese proyecto de ley se vio obstaculizado en el Senado. La Ley propuesta de Libre Elección del Empleado (Employee Free Choice Act-EFCA) tenía como objetivo volver a nivelar el equilibrio entre los trabajadores que desearan formar un sindicato y los empleadores que querían evitar la sindicalización. No obstante, la administración Obama usó herramientas sobre las que sí tenía control. Así, por ejemplo, la NLBR emitió normas que eliminaron las demoras en las elecciones de representantes sindicales, reduciendo las oportunidades para que los empleadores participasen en campañas antisindicales. También extendió los derechos de los empleados para participar en acciones colectivas a través de las redes sociales, y dictaminó que algunas grandes corporaciones no debían poder escapar de sus obligaciones como empleadores mediante la concesión de franquicias o subcontrataciones (Bivens, 2017).

En los últimos años, el Departamento de Trabajo (Department of Labor-DOL) del gobierno de Obama emitió una serie de normas que aumentaron el poder de negociación de los trabajadores de salarios bajos y medios. La más destacada fue la norma sobre el pago de horas extras, que aumentó el número de trabajadores asalariados que recibirían automáticamente el pago de horas extras, basado en un umbral salarial directo. Según las proyecciones del EPI, 12,5 millones de trabajadores se beneficiarían "directamente" de las nuevas reglas (Jamieson, 2016).

A pesar de todas estas medidas, estas reformas de Obama no tuvieron una repercusión real en una mejora de los indicadores relevantes del mercado de trabajo: empleo, tipo de empleo, salarios, dispersión salarial, nivel de sindicalización, etc. En cuanto a sus repercusiones sobre la desigualdad, cabe apuntar que la desigualdad en la etapa de Obama presentó un perfil paulatinamente creciente. El Índice de Gini pasó del 0,468 en 2009 al 0,482 en 2013, según los datos del cuadro 6. 


\section{Cuadro 6. Datos del Índice de Gini por períodos presidenciales,} 1973-2013.

\begin{tabular}{|c|c|c|c|c|c|}
\hline Años & $\begin{array}{l}\text { Índice } \\
\text { Gini }\end{array}$ & Presidencia & Años & $\begin{array}{c}\text { Índice } \\
\text { Gini }\end{array}$ & Presidencia \\
\hline 1973 & 0,400 & Richard Nixon & 1993 & 0,454 & Bill Clinton \\
\hline 1974 & 0,395 & $(1969-1974)$ & 1994 & 0,456 & $(1993-2001)$ \\
\hline 1975 & 0,397 & Gerald Ford & 1995 & 0,450 & \\
\hline 1976 & 0,398 & $(1974-1977)$ & 1996 & 0,455 & \\
\hline 1977 & 0,402 & Jimmy Carter & 1997 & 0,459 & \\
\hline 1978 & 0,402 & $(1977-1981)$ & 1998 & 0,456 & \\
\hline 1979 & 0,404 & & 1999 & 0,458 & \\
\hline 1980 & 0,403 & & 2000 & 0,462 & \\
\hline 1981 & 0,406 & Ronald Reagan & 2001 & 0,466 & George W. Bush \\
\hline 1982 & 0,412 & (1981-1989) & 2002 & 0,462 & (2001-2009) \\
\hline 1983 & 0,414 & & 2003 & 0,464 & \\
\hline 1984 & 0,415 & & 2004 & 0,466 & \\
\hline 1985 & 0,419 & & 2005 & 0,469 & \\
\hline 1986 & 0,425 & & 2006 & 0,470 & \\
\hline 1987 & 0,426 & & 2007 & 0,463 & \\
\hline 1988 & 0,426 & & 2008 & 0,466 & \\
\hline 1989 & 0,431 & George H. W. Bush & 2009 & 0,468 & Barack Obama \\
\hline 1990 & 0,428 & (1989-1993) & 2010 & 0,470 & (2009-) \\
\hline 1991 & 0,428 & & 2011 & 0,477 & \\
\hline \multirow[t]{2}{*}{1992} & 0,433 & & 2012 & 0,477 & \\
\hline & & & 2013 & 0,482 & \\
\hline
\end{tabular}

Fuente: United States Census Bureau, Historical Income Tables Income Inequality Table H-4 Gini Indexes for Households, by Race and Hispanic Origin of Householder 1967 to 2013. [Disponible en: https://www.census.gov/hhes/www/income/data/historical/inequalityl, consultado el 26 de diciembre de 2017].

\subsection{Resumen}

Como ya se ha dicho, la mayor parte del aumento de la desigualdad en la distribución de ingresos del período investigado tuvo lugar en los años ochenta y noventa. En aquellos años, el quintil y decil superiores aumentaron en más de seis y diez puntos porcentuales su participación en el ingreso total, respectivamente (cuadros 4 y 5). Sin 
duda, la política económica de Reagan tuvo una influencia directa en esta situación. También durante los años de la presidencia de George H. W. Bush (1989-1993), todos los grupos vieron reducidos sus ingresos medios, particularmente el quintil central, el de las clases medias (cuadro 5). Durante las dos presidencias de Bill Clinton (1993-2001), todos los grupos de ingresos más elevados mejoraron sus ingresos medios. De manera paralela, pero en sentido contrario, los quintiles de población hasta el $80 \%$ vieron disminuida su participación entre $-0,1$ y $-0,5$ puntos porcentuales a favor del quintil superior de ingresos, que aumentó $+1,20$ puntos. La disminución mayor se situó en los quintiles centrales (cuadros 4 y 5). Las reformas de Obama no tuvieron un impacto en la evolución de la desigualdad, ya que en la distribución del ingreso, los quintiles de menores ingresos no aumentaron su participación (cuadro 4), si bien a partir del año 2012 vieron aumentar ligeramente su ingreso familiar medio (cuadro 5) a la vez que los grupos superiores de ingresos disminuían también levemente su participación en el ingreso total.

En suma, el elevado, rápido y continuo crecimiento del ingreso medio de los hogares ubicados en los grupos más elevados de ingresos superiores, frente al debilitamiento de los grupos de renta media, ha incidido en el aumento de los grupos extremos - pobres y ricos- en los Estados Unidos. Ello ha provocado que en este país las desigualdades de renta hayan aumentado de forma apreciable desde la segunda mitad de los años setenta, pudiendo hablarse de una auténtica polarización social.

\section{Conclusiones}

En los Estados Unidos, varias reformas laborales -llevadas a cabo tanto por los presidentes republicanos como demócratas, sin grandes diferencias - han producido una degradación de las condiciones laborales de los trabajadores estadounidenses, afectando especialmente a los trabajadores de salarios más bajos, como evidencia el descenso, desde 1980, del poder adquisitivo del salario mínimo fijado por el gobierno federal. Sin duda, el descenso de la fuerza laboral sindicalizada (se podría incluso hablar de un auténtico colapso de la sindicalización), consecuencia directa de las crecientes dificultades que los empleadores, con la ayuda del gobierno, han impuesto a los trabajadores para poder sindicalizarse, ha incidido en el debilitamiento de la clase trabajadora estadounidense. El aumento de la dispersión salarial, con un impacto directo sobre la desigualdad económica ha sido otro de los efectos producidos en el mercado laboral estadounidense a lo largo del período 
investigado, así como la caída de la remuneración del trabajo en relación con su productividad.

Tras el velo ideológico del capitalismo de libre mercado, desde comienzos de la década de los años ochenta, como se ha visto, se comenzó a aplicar el recetario neoliberal en el ámbito de los mercados laborales. Y es que, la necesidad de una mayor flexibilidad laboral se convirtió en un auténtico mantra constantemente repetido por los organismos económicos nacionales e internacionales - OCDE, FMI, BCE, etc.- en sus reiteradas presiones a los gobiernos para que actuasen en ese sentido. Cualquier reforma laboral era insuficiente para esos organismos y, por lo tanto, no cesaban las recomendaciones de nuevas reformas flexibilizadoras, que desregularizasen más aún los mercados de trabajo. Bajo este marco [des]regulatorio neoliberal, en Estados Unidos se llevaron a cabo reformas laborales, en sintonía con las adoptadas en muchos otros países, que estuvieron dirigidas a la flexibilización del mercado de trabajo, afectando a una variedad de aspectos, como el distanciamiento del salario mínimo del mediano, la reducción de los costes de despido o la disminución del poder sindical, entre otros.

Podría decirse que las reformas del mercado de trabajo llevadas a cabo a lo largo del período de análisis -marcadas, en general, por una legislación profundamente laxa con las obligaciones de los empresarios e intensamente restrictiva con los derechos de los trabajadores- han determinado una transformación en el universo del trabajo a partir de la década de los años ochenta, tendiendo a configurar un nuevo modelo de relaciones laborales de carácter neoliberal y al servicio de la competitividad empresarial, brindando a las empresas más flexibilidad en todos los ámbitos laborales.

La puesta en marcha y consolidación de este modelo de acumulación de signo globalizador y neoliberal, sin duda, ha contribuido a que las desigualdades laborales se agudizaran, lo que permitiría entender y justificar el aumento paulatino y creciente de la desigualdad económica producido en los Estados Unidos.

Se ha documentado que los distintos presidentes a lo largo del período bajo análisis no han articulado políticas de progreso para los trabajadores estadounidenses. Ni los presidentes republicanos ni los demócratas se han diferenciado mucho en las reformas laborales impulsadas, sin recato en mostrar su trato de favor hacia las empresas, en algunos casos, con un componente más social, en otros, pero con resultados similares sobre la clase trabajadora y en contra del legado que el New Deal hizo a la sociedad de los Estados Unidos. 
Obviamente, a pesar de que, seguramente, el principal factor determinante del aumento de la desigualdad económica en los Estados Unidos ha estado en el interior del mercado laboral, la ampliación de la brecha en la distribución de los ingresos entre los hogares estadounidenses no ha provenido solamente de las reformas del mercado de trabajo, sino que se entiende que habría que analizar también el papel desempeñado por la política pública fiscal así como la relacionada con el gasto público social como factores redistributivos o compensadores o no de la desigualdad económica.

\section{Referencias bibliográficas}

Álvarez, N., Buendía, L., Mateo, J., Medialdea, B., Molero, R., Montanya, M., Paz, M. J. y Sanabria, A. (2009). Ajuste y salario. Las consecuencias del neoliberalismo en América Latina y Estados Unidos, Madrid: Fondo de Cultura Económica de España.

Álvarez Peralta, I. y Buendía García, L. (2004). "Financiarización y regresión social: la economía de los EE.UU. durante los años noventa". Ponencia presentada en las IX Jornadas de Economía Crítica, Madrid 2527 de marzo.

American Federation of Labor-Congress of Industrial Organizations (AFL-CIO) (2004). The Bush Record on Shipping Jobs Overseas. Cornell University ILR School, Key Workplace Documents 8.

Arroyo Vázquez, M $M^{\mathrm{a}}$ L. (2002). "Un hito de la legislación laboral estadounidense: la ley nacional de relaciones laborales o ley Wagner (1935)". Espacio, Tiempo y Forma, Serie V, Hª Contemporánea, 15: 351377.

Atkinson, Anthony B. (2015). Inequality. What can be done?, Cambridge: Harvard University Press.

Autor, D. H.; Katz, L. F. y Kearney, M. S. (2008). "Trends in U.S. wage inequality: Revising the revisionists". The Review of Economics and Statistics 90 (2): 300-323.

Bivens, J. (2017). The Obama legacy on wages, Working Economics Blog, Economy Policy Institute (EPI), January 10. 
Chomsky, N. (2016). ¿Quién domina el mundo?, $2^{\text {a }}$ edición, Barcelona: Ediciones B, S.A.

Dark III, T. E. (2008). "Representing Labor in Congress: The enduring quest for Labor Law Reform". Annual Meeting of the Western Political Science Association, Chicago, Illinois, March 20-23.

Dark III, T. E. (2009). "Prospects for Labor Law Reform". Perspectives on Work (Summer 2008/Winter 2009): 23-26.

Díez Espinosa, J. R., Martín de la Guardia, R., Martínez de Salinas Alonso, Mª L., Pelaz López, J. V., Pérez López, P. y Pérez Sánchez, G. A. (2006). Historia del mundo actual (desde 1945 hasta nuestros dias), $3^{a}$ edición revisada y ampliada. Valladolid: Secretariado de Publicaciones e Intercambio Editorial, Universidad de Valladolid.

Faux, J. (2008). La guerra global de clases: cómo nos robaron el futuro las élites de Estados Unidos, Canadá y México y qué hacer para recuperarlo. México, D.F.: Universidad Autónoma de la Ciudad de México.

Flynn, J. (2000). "A Quiet Revolution at the Labor Board: The Transformation of the NLRB, 1935-2000". Ohio State Law Journal 61 (4): 1361-1455.

Fontana Lázaro, J. (2011). Por el bien del Imperio. Una historia del mundo desde 1945. Barcelona: Pasado y Presente.

Fontana Lázaro, J. (2017). El siglo de la revolución. Una historia del mundo desde 1914. Barcelona: Editorial Planeta.

Friedman, G. (2008). Labor Unions in the United States. EH.net Encyclopedia, editada por Robert Whaples.

Galenson, D. W. (1984). "The Rise and Fall of Indentured Servitude in the Americas: An Economic Analysis". Journal of Economic History 44 (1): 1-26.

García Pérez, R. (2009). "Del «nuevo orden» de G. Bush al «eje del mal» de G.W. Bush (1991-2008)", en J. C. Pereira (coord.), Historia de las relaciones internacionales contemporáneas, $2^{\mathrm{a}}$ edición. Barcelona: Ariel, 657-674. 
Goldin, C. (1993). "The Political Economy of Immigration Restriction in the United States, 1890 to 1921". NBER Working Paper Series, Working Paper 4345, Cambridge: National Bureau of Economic Research.

Goldin, C. (2000). "Labor Markets in the Twentieth Century", en S. Engerman y R. E. Gallman (eds.), The Cambridge Economic History of the United States, Volume 3: The Twentieth Century. Cambridge: Cambridge University Press: 549-624.

Gordon, R. J. (2009). "Misperceptions about the magnitude and timing of changes in American Income Inequality". Working Paper 15351, Cambridge, National Bureau of Economic Research: 26-27.

Grubb, F. (1985). "The Market for Indentured Immigrants: Evidence on the Efficiency of Forward Labor Contracting in Philadelphia, 1745-1773". Journal of Economic History 45 (4): 855-868.

Grubb, F.(1986). "Redemptioner Immigration to Pennsylvania: Evidence on Contract Choice and Profitability". Journal of Economic History 46 (2): 407-418.

Gurriere, V. (2017). "Obama's Biggest Employment Policy Hits And Misses", law360.com, 13 de enero.

Harvey, D. (2007). Breve historia del neoliberalismo. Madrid: Ediciones Akal.

Howell, D. R. (1999). Theory-Driven Facts and the Growth in Earnings Inequality. Review of Radical Political Economics 31 (1): 54-86.

Jamieson, D. (2016). "Obama Is Bringing Overtime Pay to Millions of Workers", Huffpost.com, 17 de mayo.

Kilberg, W. J.. Schwartz, J. y Chadwick, J. (2009). "A measured approach: empleoyment and labor law during the George W. Bush years". Harvard Journal of Law \& Public Policy 32 (3): 997-1013.

Laval, Christian y Dardot, Pierre (2015). La nueva razón del mundo, $2^{\mathrm{a}}$ edición. Barcelona: Gedisa. 
Lee, D. S. (1999). "Wage inequality in the U.S. during the 1980s: rising dispersion or falling minimum wage?". Quarterly Journal of Economics 114 (3): 977-1023.

Levy, F. y Temin, P. (2007). "Inequality and Institutions in $20^{\text {th }}$ Century America". NBER Working Paper Series. Working Paper 13106. Cambridge: National Bureau of Economic Research.

Meyer, B. D. y Sullivan, J. X. (2011). "The Material Well-Being of the Poor and the Middle Class Since 1980". Working Paper 2011-04, American Enterprise Institute for Public Policy Research Working.

Morgan, E. S. (1971). "The Labor Problem at Jamestown, 160718". American Historical Review 76 (3): 595-611.

Nadal, A. (2010). "Del Tratado de Detroit a Goldman Sachs". La Jornada, 21 de abril.

Organisation for Economic Cooperation and Development (OECD) (2011). Divided We Stand. Why Inequality Keeps Rising? París: OCDE.

Osterman, P. (1999). Securing Prosperity-The American Labor Market: How It Has Changed and What to Do about It. Princeton: Princeton University Press.

Palazuelos Manso, E. (2010). "Estados Unidos 1981-2008: un modelo de crecimiento agotado", en M.E. Correa Vázquez y E. Palazuelos Manso (coord.), Opacidad y hegemonía en la crisis global. Madrid: Catarata: 93120.

Panitch, L. y Gindin, S. (2015). La construcción del capitalism global. La economía política del imperio estadounidense. Madrid: Ediciones Akal, S.A.

Pollin, R. (2000). "Análisis de la política económica de Clinton". New Left Review 4: 15-41.

Pollin, R. (2005). Los contornos del declive, Traducción de Juan Mari Madariaga. Madrid: Ediciones Akal.

Pollin, R. y Luce, S. (1998). The Living Wage: Building a Fair Economy. New York: New Press. 
Roomkin, M. (1981). "A Quantitative Study of Unfair Labor Practice Cases". Industrial and Labor Relations Review 34 (2): 245-256.

Rosenbloom, J. (2008). The History of American Labor Market Institutions and Outcomes, EH.net Encyclopedia, editada por Robert Whaples, March 16.

Ruiz-Huerta Carbonell, J. (1998). "Mercado de trabajo y desigualdad: el papel de las políticas públicas". V Encuentro de Economía Pública: La Realidad de la Solidaridad en la Financiación Autonómica, enero 1998.

Stiglitz, Joseph E. (2017). La gran brecha, Barcelona: Penguin Random House Grupo Editorial.

Vittoz, S. (1987). New Deal Labor Policy and American Industrial Economy. London: The University of North Carolina Press.

Wolters, R. (1990). "Section $7^{\mathrm{a}}$ and the Black Worker", en M. Dubofsky (ed.), The Great Depression and the New Deal. New York: Garland Publishing, Inc.: 22-27.

Wright, G. (1986). Old South, New South: Revolutions in the Southern Economy since the Civil War. New York: Basic Books.

Zappone, C. (2007). "Minimum wage boost first in 10 years". CNNMoney.com, 23 de Julio.

Zinn, H. (2001). La otra historia de los Estados Unidos (desde 1492 hasta hoy), $2^{a}$ edición. New York: Siete Cuentos Editorial. 